NBER WORKING PAPER SERIES

\title{
LOCAL PROTECTIONISM, MARKET STRUCTURE, AND SOCIAL WELFARE: CHINA'S AUTOMOBILE MARKET
}

\author{
Panle Jia Barwick \\ Shengmao Cao \\ Shanjun Li \\ Working Paper 23678 \\ http://www.nber.org/papers/w23678 \\ NATIONAL BUREAU OF ECONOMIC RESEARCH \\ 1050 Massachusetts Avenue \\ Cambridge, MA 02138 \\ August 2017
}

We thank Matt Backus, Steve Coate, Penny Goldberg, Paul Grieco, Jean-Francois Houde, Ivan Png, Paolo Ramezzana, Fan Ying, and seminar participates at Arizona State University, Cornell University, Cornell-Penn State Econometrics and IO Conference, Federal Trade Commission, HEC Montreal Conference on IO, Indiana University, NBER Chinese Economy Working Group, New York IO Day Conference, Peking University, University of California-Davis, and University of Wisconsin for helpful comments. We acknowledge generous data sharing from Tao Chen, Rui $\mathrm{Li}$, and Xiaobo Zhang. Ke Liu, Binglin Wang and Jingyuan Wang provided excellent research assistance. The views expressed herein are those of the authors and do not necessarily reflect the views of the National Bureau of Economic Research.

NBER working papers are circulated for discussion and comment purposes. They have not been peer-reviewed or been subject to the review by the NBER Board of Directors that accompanies official NBER publications.

(C) 2017 by Panle Jia Barwick, Shengmao Cao, and Shanjun Li. All rights reserved. Short sections of text, not to exceed two paragraphs, may be quoted without explicit permission provided that full credit, including $\odot$ notice, is given to the source. 
Local Protectionism, Market Structure, and Social Welfare: China's Automobile Market

Panle Jia Barwick, Shengmao Cao, and Shanjun Li

NBER Working Paper No. 23678

August 2017

JEL No. D04,D6,F15,H2,L1,L5,L62

\begin{abstract}
While China has made great strides in transforming its centrally-planned economy to a marketoriented economy, there still exist widespread interregional trade barriers, such as policies and practices that protect local firms against competition from non-local firms. This study documents the presence of local protectionism and quantifies its impacts on market competition and social welfare in the context of China's automobile market. This market exhibits a salient feature that vehicle models by joint ventures (JVs) and especially state-owned enterprises (SOEs) command much higher market shares in their headquarter province than at the national level. Through spatial discontinuity analysis at provincial borders, falsification tests, and consumer surveys, we first confirm protective policies such as subsidies to local brands as the primary contributing factor. We then set up and estimate a market equilibrium model to quantify the impact of local protection, controlling for other demand and supply factors. Counterfactual simulations show that local protection leads to significant choice distortions, resulting in 18.7 billion yuan of consumer welfare loss, amounting to $40 \%$ of total subsidy. Provincial governments face a prisoner's dilemma: according to our estimates, local protection reduces aggregate social welfare, but the provincial governments have no incentive to unilaterally remove local protection.
\end{abstract}

Panle Jia Barwick

Department of Economics

Cornell University

462 Uris Hall

Ithaca, NY 14853

and NBER

panle.barwick@cornell.edu

Shengmao Cao

Economics Department

Stanford University

Stanford, CA 94305

shengmao@stanford.edu
Shanjun Li

Cornell University

405 Warren Hall

Ithaca, NY 14853

and NBER

SL2448@cornell.edu 


\section{Introduction}

Since the implementation of market reform and open-up policy in 1978, China has made great strides in transforming its centrally-planned economy to a market-oriented economy. By recognizing private ownership, unleashing entrepreneurial spirit, and promoting international trade, the reform has led to an unprecedented economic growth with an annual GDP growth rate of 10 percent for over 35 years. ${ }^{1}$

Despite tremendous progress made in integrating with the world economy, China's domestic market still exhibits widespread interregional barriers to trade that limit the mobility of goods and services. These barriers impede market integration and could lead to substantial welfare losses (Donaldson, 2015). One such barrier results from policies and practices that protect local firms against competition from non-local firms, which we characterize as local protectionism. Local protectionism arises from a combination of factors: the top-down political personnel system that relies heavily on local GDP growth for promotion, rent-seeking behaviour of local officials who are closely connected to local SOEs or JVs, and the lack of effective regulations from the central government.

Local protectionism in China takes many forms, including explicit discounts for local brands and implicit barriers for non-local brands. Due to the nature of these policies (many of which are opague and implicit), collecting systematic data that incorporate all different forms of protection is infeasible. Instead, using the census of vehicle registration records from 2009 to 2011, we provide convincing evidence that local protectionism exists in China's automobile market and use a structural model to quantify the extent of local protection and its welfare consequences.

Our point of departure is the striking empirical pattern that vehicle models produced by stateowned enterprises (SOEs) and joint ventures (JVs) command a much higher market share in their headquarter province than at the national level, a phenomenon that we call 'home bias'. ${ }^{2}$ Through a spatial regression discontinuity design (henceforth RD) and a series of falsification tests, our empirical analysis rules out a host of alternative explanations and establishes local protectionism as the primary contributing factor to home bias. This is carried out through the following steps.

First, we present evidence that home bias persists after controlling for consumer demographics, distance and transportation costs, dealer networks, and a variety of geographic and temporal fixed effects. Then we employ the spatial RD method and focus on clusters of adjacent counties on

\footnotetext{
${ }^{1}$ This process was unfolded in three major waves: the reform in the agricultural sector that started in 1978 and made farmers residual claimants, the privatization of State-own Enterprises (SOEs) from the late 1980's, and the entry to WTO in 2001, respectively.

${ }^{2}$ Home bias is well documented in the trade, finance, and marketing literature (French and Poterba, 1991; McCallum, 1995; Klein and Ettensoe, 1999). It is typically though not exclusively observed in the international context with respect to products from different countries (e.g., a country-of-origin effect). Our analysis focuses on interregional trade and the home bias we study is a province-of-origin effect (based on the location of vehicle assembly) within a country.
} 
different sides of provincial borders to control for unobserved consumer preference that favor local products. We show that strong home bias persist within these county clusters: even though counties within a cluster have similar culture, customs, consumer demographics and access to dealer stores, SOE and JV products command much higher market shares in counties located in their headquarter province than in the adjacent counties across the province border. In contrast, home bias is absent for models produced by private automakers, a pattern that is robust across various specifications. Adding controls such as the distance to the production county, the number of dealers, and employee discount programs do not change the key coefficients. These results provide evidence that the observed pattern of home bias is unlikely to be driven by consumer preference (since we focus on clusters of adjacent and similar counties), or by consumer ethnocentrism that favor local products (which would have led to a similar home market advantage by private firms).

Second, we conduct falsification tests to examine the key identification assumption of our RD analysis: no discontinuity in unobserved demand factors or supply factors at the provincial boundary. The assumption could be violated if local SOE or JV products have attributes that are more suited to tastes of local consumers or if SOEs and JVs advertise heavily on local channels. Our falsification tests indicate that non-local products that are most similar in attributes to local SOE or JV products do not enjoy any sales advantage in local products' home market. In addition, focusing on the set of non-producing provinces (provinces that do not have any auto firms) and using a similar spatial RD analysis, we find no systematic evidence that SOE or JV products are favored in any set of counties across the border of non-producing provinces. Finally, evidence from a 2012 national survey of vehicle owners rules out local TV advertising as an important confounding factor. Less than $12 \%$ of survey correspondents choose TV advertising (including both national and local TV advertising) as a source of information and only $2.1 \%$ consider TV advertising as the most influential channel in their purchase decisions. ${ }^{3}$

Third, to gauge directly consumers' awareness of local products by firm ownership status, we conducted a survey of 297 car shoppers in a large municipality in China during November 2016. Our questionnaire (see Appendix C) includes ten simple single-choice questions on two local firms and five other major auto firms. The majority of respondents cannot identify the ownership type or local status of the two firms that are headquartered in the city where they live, indicating limited awareness of firm type. In a market where most consumers are first-time buyers and firm/brand recognition is a new phenomenon, consumer favoritism is unlikely to be an important factor.

Our results from spatial RD regressions, falsification tests, and car buyer surveys all point to local protective policies instead of consumer preference heterogeneity as the key driver of home bias. While it is impossible to obtain an exhaustive list of such policies, we have uncovered a series

${ }^{3}$ Local TV channels accounted for less than $20 \%$ of national TV viewership (2011 China TV Rating Yearbook). There is no evidence from auto firms' annual reports that SOE or JV auto firms spend significant amount of resources advertising on local channels. 
of them that target SOE and JV products (see section 2 for more details).

To understand the impacts of local protectionism on market competition and social welfare, we set up and estimate a market equilibrium model in the spirit of Berry et al. (1995), incorporating local protectionism as a price subsidy on local products. Our estimation results suggest that local protectionism (including explicit subsidies and implicit barriers) is equivalent to a price discount of $28 \%$ for SOE products and $17 \%$ for JV products, which leads to a sales increase of about $245 \%$ for SOEs and $61 \%$ for JVs in their headquarter province. Second, estimated subsidies and other preferential treatment amount to 46.3 billion Yuan from 2009 to 2011. Finally, these policies are regressive: $78 \%$ of its benefits go to the top $10 \%$ richest households.

Counterfactual simulations show that choice distortions induced by local protectionism lead to a consumer welfare loss of 11 billion Yuan. When we take into consideration the price adjustment by auto firms, consumer welfare loss rises to 18.7 billion Yuan, or $\$ 2.8$ billion. To put things into perspective, this is equivalent to $40 \%$ of the estimated total subsidy. Even if we were to ignore the excess burden of collecting taxes to finance these subsidies (17 to 56 cents for each dollar of tax revenued collected (Ballard et al., 1985)), this is evidence that protective policies, such as the ones studied here, are highly wasteful and generate substantial welfare losses.

Perhaps not surprisingly, the auto industry as a whole benefits from local protection: aggregate industry profits increase by 8.1 billion yuan consequently. However, these policies lead to a redistribution among firms: high-cost SOEs and JVs benefit at the expense of more efficient private automakers. In addition, some high-cost firms (e.g. Xiali) would have been unprofitable in the absence of local protection.

Our analysis also highlights a prisoner's dilemma. Implementing local protection is the dominant strategy for provincial governments since gains in local firm profits loom larger than consumer welfare loss. However, our estimates suggest that the overall society is worse off with local protection because of the negative externalities on non-local firms. Eradicating these discriminatory polices therefore requires effective oversight by the central government (e.g., enforcement of the anti-unfair competition law).

Our study makes the following three contributions to the literature. First, it adds to the literature on understanding brand preferences and market share dynamics (Bronnenberg et al., 2012). In the automobile market, the most closely related papers include Goldberg and Verboven (2011) (which documents evidence of home bias across European countries) and Cosar et al. (2016) (which shows that consumer preference for domestic brands is the main contributing factor for home bias). We contribute to this literature by showing that local governments' policies and practices could be another important factor in shaping the geographic variation in market shares. ${ }^{4}$ In contrast to

${ }^{4}$ Klier and Linn (2013) show that regulatory policies such as the fuel tax and the emission standards could favor local products relative to the products from other countries-of-origin. For example, U.S. has a more stringent tailpipe emission standards on nitrogen oxides than EU. This puts diesel vehicles (mainly produced by EU automakers) in a 
the finding from Cosar et al. (2016), consumer preference is unlikely to be the main driver of home bias in our context for several reasons. Chinese passenger car industry, despite its large size, has only fifteen years of history and is much less mature compared to the global auto industry which originated in the 1860s. Consumer brand loyalty is still in its infant stage: most Chinese vehicle buyers are first-time buyers, with $75 \%$ of them citing word-of-mouth as the most important information channel for their car purchase (National Information Center 2012). In addition, our identification strategy is different from theirs. We rely on spatial RD and compare demand patterns among adjacent counties. Lastly, we examine consumer demand within a country. Factors that arise more naturally in an international setting (e.g. consumer ethnocentrism) are unlikely to be at play in our context.

Second, our paper is related to the emerging literature on understanding intra-national trade barriers and spatial patterns of production specialization. Within the trade literature, recent studies have quantified the importance of geography in trade costs using data from both developing and developed countries (Anderson et al., 2014; Donaldson, 2017; Cosar and Fajgelbaum, 2016; Head and Mayer, 2016). Our paper points to local protective policies as another source of trade costs. These discriminatory policies against non-local firms are hard to measure since they vary across space and time and are often implicit. Using province-level industry aggregate output, previous studies have provided evidence of local protectionism by detecting regional specialization that deviates from comparative advantage of input factors (Young, 2000; Bai et al., 2004; Holz, 2009). Our study documents local protectionism in a consumer good industry by showing that local products enjoy home bias that cannot be explained by transportation cost, sales network, and preference heterogeneity. More importantly, our paper is the first to quantify the impacts of local protectionism on market outcomes and social welfare, an important step toward understanding the market structure in an emerging economy.

Third, our paper contributes to the literature on understanding the sources of resource misallocation and the implications on productivity and economic growth (Fajgelbaum et al., 2016; Hsieh and Klenow, 2009; Brandt et al., 2009). These studies have primarily focused on the input market. Different from the previous literature, our analysis focuses on the market frictions induced by government policies in a product market. We show that such frictions change the relative prices of products based on their origin of production, resulting in inefficient production allocation and ultimately misallocation of inputs across heterogeneous firms. A better understanding of how interregional trade barriers (including local protectionism) affect market competition and social welfare has important implications for policies in both China and other developing countries facing such barriers.

competitive disadvantage in the U.S. market. In addition, the Corporate Fuel Economy (CAFE) Standards in the U.S. are less stringent for light trucks (SUVs, pickup trucks, and vans) than passenger cars, implicitly favoring the Big Three. 
The rest of the paper is organized as follows. Section 2 and 3 give an overview of China's automobile industry and our data sets and present descriptive evidence of local protectionism. Section 4 uses a spatial regression discontinuity analysis, falsification tests, and consumer surveys to establish local protectionism as the leading explanation for home bias. Section 5 sets up a market equilibrium model of vehicle demand and supply and discusses the identification strategy. Section 6 presents results from the structural model. Section 7 conducts simulations to quantify the welfare impact of local protectionism. Section 8 concludes.

\section{Background and Data}

In this section, we first present anecdotal evidence of local protectionism and discuss the relevant institutional background. We then provide an overview of China's automobile industry and describe the data.

\subsection{Local Protectionism}

We define local protectionism as policies and practices that protect local firms against competition from non-local firms. In the passenger automobile market, a common practice is to give consumers direct subsidies or tax incentives for purchasing local products, where the definition of a "local" product is tied with different requirements across jurisdictions. ${ }^{5}$

From online searches with the keywords "subsidy + promote automobile industry", we compile a list of over 100 recent policies that subsidize buyers of local brands using direct monetary transfer, tax and fee waivers, or low-interest loans. Table 1 presents ten cases of subsidies for products that are produced either by designated local automakers or in the jurisdiction. The 7th case is worth noting in that the subsidy only applies to indigenous brands produced by the state-owned subsidiaries of the First Auto Works group (henceafter FAW), but not to the brands by the JV subsidiaries of FAW. ${ }^{6}$ Provinces that come up frequently in this list(e.g. Guangxi, Heilongjiang) are among the ones where we observe the largest home bias for local JVs and SOEs.

Besides direct subsidies, local protectionism comes in many other forms: taxes levied on nonlocal products, explicit requirements for government agencies and taxi companies to purchase local brands; procurement priority or tailpipe emission standards that favor local brands; and explicit and implicit barriers for non-local brands to establish dealer network. The common theme of the

\footnotetext{
${ }^{5}$ Yu et al. (2014), an article in Wall Street Journal on 5/23/2014, reports that government subsidy to 22 publicly traded automakers in China amounted to 2.1 billion Yuan in 2011 and this number increased to 4.6 billion in 2013. The article acknowledges that " $(\mathrm{t})$ he subsidies come in many forms, including local government mandates and subsidies for purchases of locally made cars, making a total figure for local and national financial help difficult to calculate." ${ }^{6} \mathrm{FAW}$ is one of the largest automakers in China. It has three state-owned subsidiaries producing indigenous brands such as Besturn and three JV subsidiaries producing Volkswagen, Toyota, and Mazda models.
} 
Table 1: Examples of Local Protectionism

\begin{tabular}{llllll}
\hline Case & From & To & Location & Size & Eligibility \\
\hline 1 & $3 / 1 / 09$ & $12 / 31 / 09$ & Hebei & $10 \%$ or 5000 Yuan & Local minivans \\
2 & $7 / 1 / 09$ & $12 / 31 / 09$ & Heilongjiang & $15 \%$ or 7500 Yuan & Local brands \\
3 & $8 / 18 / 09$ & unkown & Henan & $3 \%$ or 1500 Yuan & Local brands in Henan \\
4 & $3 / 07 / 11$ & unknown & Guangxi & Lower purchase tax & Local brands \\
5 & $1 / 1 / 12$ & $12 / 31 / 12$ & Chongqing & Total 300 mill. Yuan & Changan Automotive \\
6 & $4 / 4 / 12$ & $12 / 31 / 12$ & Anhui & 3000 Yuan & Local brands for Taxi \\
7 & $7 / 1 / 12$ & $6 / 30 / 13$ & Changchun, Jilin & $3500-7000$ Yuan & FAW indigenous brands \\
8 & $5 / 1 / 15$ & $4 / 30 / 16$ & Fuzhou, Jiangxi & $5 \%-10 \%$ & Jiangling Automotive \\
9 & $11 / 15 / 15$ & $12 / 15 / 15$ & Guangxi & $1500-2000$ Yuan & Local brands \\
10 & $12 / 21 / 15$ & unknown & Harbin & Up to 60\% & Local electric vehicles \\
\hline
\end{tabular}

Source: Official government documents from online searches.

stated rationale behind these policies in official government documents is to increase employment, strengthen the local automobile industry and in turn the local economy. A famous example of local protectionism is the 'war of license fees' between Shanghai and Hubei province in the late 1990s. Starting from the early 1990s, Shanghai municipal government implemented Reserve Price auctions for vehicle license plates. Vehicle buyers were required to pay for the license plate before registering their newly purchased vehicles. In 1999, in the name of promoting the growth of local automobile industry, Shanghai government set the reservation price to 20,000 yuan for local brands (e.g. Santana produced by Shanghai Automotive) and 98,000 yuan for non-local brands. In retaliation, Hubei province, the headquarter province of China's Second Automotive Group (also known as Dongfeng Auto), charged an extra fee of 70,000 yuan to Santana buyers "to establish a fund to help workers of companies going through hardship" .

It is important to note that local protection and trade barriers that we analyze here are not about physical barriers related to a poor transportation infrastructure. China has built up impressive transportation systems (air, highway, rail, and water) and logistic networks during the past two decades, drastically reducing the transportation cost of moving goods and services (Faber, 2014). With the first highway built in 1988, China now has the largest highway network in the world with the total length of $131,000 \mathrm{~km}$ by 2016 , compared to $77,000 \mathrm{~km}$ in the United States. China has the second longest railways of $124,000 \mathrm{~km}$ and world's longest high-speed rail network of $19,000 \mathrm{~km}$ by 2016 .

Local protectionism in China arises from a combination of factors. First, market reforms started in 1978 made economic development the primary responsibility of local governments. GDP growth became the foremost measure of performance in the top-down political personnel system where local officials (provincial governors, city and county mayors) are evaluated by government officials 
at the higher level. ${ }^{7}$ In addition, the fiscal decentralization whereby local expenditures are mostly financed by local revenue provides officials incentives to seek a strong local economy (Jin et al., 2005). There often exists a dynamic and reciprocal relationship between local government and firms: governments favor connected firms through better access to credit and tax deductions while firms return the favors in providing assistance such as tax revenue to local governments (Lei, 2017). Both the promotion system and fiscal decentralization lead to inter-jurisdictional competition and discriminatory policies that protect local firms against competition from non-local firms.

Second, local government officials often derive private benefits from local SOEs and JVs. Local governments appoint the top executives of SOEs and JVs in their jurisdiction and there exists a revolving door between top executives in these companies and government officials. As a result, local government officials can directly benefit from local SOEs in many ways, ranging from finding jobs for their relatives in these companies to eliciting monetary support for public projects and even private usage. $^{8}$

Third, the central government has not been very effective in regulating inter-regional trades. While the literature of fiscal federalism points out the potential benefit of allowing local governments to make better-informed decisions on public goods provision, it also acknowledges the pitfalls of regional protectionism and allocative distortions (Oats, 1972). The central government plays an important role in addressing these pitfalls through promoting a national market and eliminating trade barriers. The Commerce Clause in the U.S. Constitution explicitly prohibits state regulations that interfere with or discriminate against interstate commerce. This to a large extent frees the U.S. market of local protective policies observed in China, although some inter-state trade barriers also persist in the U.S. (Fajgelbaum et al., 2016). Although China's Anti Unfair Competition Law that was passed in 1993 explicitly prohibits municipal or provincial governments from giving preferential treatment to local firms, enforcement of the law has been ineffective. ${ }^{9}$

The intensity of local protection is different for local forms of different ownership types. SOEs are treated most favorably because of their importance in the local economy and close ties between SOE top executives and local government officials. JVs lie between SOEs and private firms in the spectrum of differential treatment. By law, JVs are owned in majority by Chinese automakers and in practice, the Chinese partners are all SOEs. In the empirical analysis, we measure the degree of local protection for SOEs, JVs, and private automakers separately. Consistent with Bai et al. (2004)

\footnotetext{
${ }^{7}$ Effective implementation of the one-child policy also used to be an important criterion. In recent years, environmental measures are added to the evaluation system.

${ }^{8}$ This has been highlighted by many recent high-profile corruption cases in China where government officials were convicted of taking eye-popping bribes from executives of large companies in their jurisdiction.

${ }^{9}$ The protective practices are likely in violation of the National Treatment Principle of WTO which prohibits discrimination in terms of internal taxation and other regulations between imported and domestically produced goods. However given the small market share of imports and virtually all international auto makers have JVs in China, there have not been trade challenges on this ground from other countries.
} 
which finds stronger local protectionism in industries where SOEs account for a larger output share, our empirical analysis shows that local protectionism benefits SOEs the most and JVs the second.

\subsection{The Chinese Automobile Industry}

Like many other industries, China's automobile industry grew from virtually non-existent thirty years ago to the largest in the world during the past two decades. Figure 1 depicts the annual sales of new passenger vehicles in U.S. and China. The total number of new passenger vehicle sales in China increased from 0.85 million in 2001 to 21.1 million in 2015, surpassing the U.S. in 2009. The growth in China's automobile market during this period accounted for about 75 percent of the growth in the world automobile market.

Figure 1: New Passenger Vehicle Sales in China and U.S.

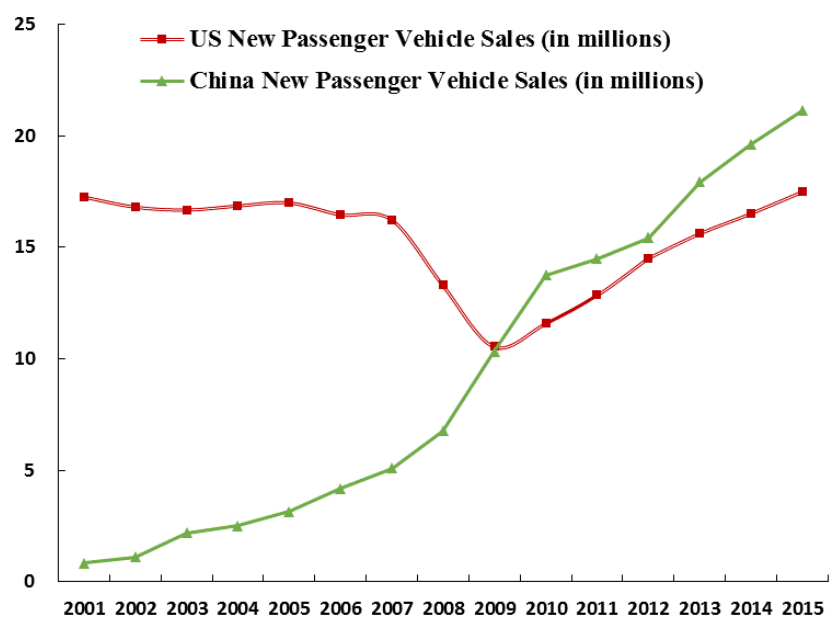

All major international automakers currently have production capacity in China. Following the strategy of "exchange-market-for-technology", or "Quid Pro Quo" (Holmes et al., 2015), Chinese government requires foreign automakers to form joint ventures with domestic automakers in order to set up a production facility. The non-Chinese parties combined in a joint venture cannot claim more than 50 percent of the ownership. One underlying rationale behind such a requirement is to help domestic automakers to learn from foreign automakers and eventually compete in the international market. Volkswagen was the first to enter the Chinese market by forming a JV with Shanghai Automotive in 1983. To date, Volkswagen and GM have the largest presence in China among foreign automakers. During our sample period, joint ventures contribute to $68.7 \%$ of total sales. Private automakers, SOEs, and imports account for $11.4 \%, 16.7 \%$ and $3.1 \%$ of total sales, respectively. 
For its potentially large contribution to local employment and GDP and its spillover benefits to upstream industries, the automobile industry is a frequent target for government protection. Provinces compete to provide financial incentives to attract automakers. As a result, automobile production currently exists in 22 out of 31 provinces. During China's 11th Five Year Plan from 2005 to 2010, all of these provinces designated the automobile industry as a strategic industry that enjoy tax benefits and various other government support.

Perhaps not surprisingly, China's automobile market is much less concentrated and the average output of each automaker is small compared to the U.S.. In 2015, there are over 60 automakers producing in China and the top six dominant firms account for $46 \%$ of the national sales. After years of rapid expansion, the Chinese auto industry is plagued with overcapacity, with an average capacity utilization rate of merely $64 \%$. In contrast, in the U.S., there are fifteen automakers and the top six firms control $77 \%$ of the market. Automobile assembly plants are located in 14 out of 50 states, with an average capacity utilization rate around $85 \% .^{10}$

\subsection{Data}

Our analysis is based on four main data sets: (1) the universe of vehicle registration records from 2009 to 2011 that is compiled by the State Administration of Industry and Commerce, (2) trim level vehicle attributes from R. L. Polk \& Company (henceforth Polk), (3) city level household demographics from the 2005 one-percent population survey, and (4) an annual survey of new vehicle buyers by Ford Motor Company.

For the vehicle registration data, we observe the month and county of registration, the brand and model name of the vehicle registered, as well as major attributes such as transmission type, fuel type, and engine size. We also observe whether the license is for an individual or institutional purchase. Institutional purchases account for about $10 \%$ of all registration records. This is very different from Europe where half of new vehicle registrations belong to company cars (Dimitropoulos et al., 2014). We exclude institutional purchases in this study since they are often driven by non-market considerations that require different modeling assumptions.

We aggregate data to the model-county level for the spatial discontinuity analysis in Section 4, and to the model-province level for the structural estimation in Section 5. To translate the number of registration records, or sales, into market shares, we define market size as the number of Chinese households in each province. ${ }^{11}$

\footnotetext{
${ }^{10}$ According to a 2013 OECD report titled "Medium-Run Capacity Adjustment in the Automobile Industry", the capacity utilization in China's automobile industry was 64 percent in 2012, compared to 83 percent in both U.S. and Japan and 84 percent in Germany.

${ }^{11}$ While some consumers might purchase a new vehicle in one province and register it in another province, this is uncommon since dealers typically bundle services with the sale price of a new vehicle.
} 
The trim-level vehicle attributes include the manufacturer suggested retail price (MSRP), vehicle type (sedan, SUV, or MPV), vehicle size $\left(\mathrm{m}^{2}\right)$, engine size (liter), horsepower (kilowatts), weight (ton), transmission type, and fuel type. MSRPs are set by manufacturers and are the same nationwide for each model-year. Discounts offered by individual dealers may lead to transaction prices that are different from the MSRPs. According to a 2016 store-level promotion data that is discussed in detail in Appendix B, regional variations in retail prices are modest. ${ }^{12}$ MSRP is a reasonable approximation of the unobserved transaction price for two reasons. First, heavy discounts are rare: around $40 \%$ of trim-by-store observations have no discount, $25 \%$ have a $10 \%$ discount, and only $3 \%$ have a $20 \%$ discount. More importantly, dealer stores do not give more discount to local products, which suggests that using MSRP in place of the transaction price should not introduce bias in the estimation of local protection.

MSRP in China includes value-added tax, consumption tax, as well as import tariffs when applicable. ${ }^{13}$ It does not include sales tax, which is usually $10 \%$ except for vehicles with engine displacement no more than 1.6 liter in 2009 and 2010, which have sales tax rates of 5\% and 7.5\% respectively. We add sales tax to MSRP, and deflate it to the 2011 level to obtain the real transaction price paid by consumers. We choose engine size over horsepower-to-weight ratio as a measure of acceleration because engine size is known to be a more salient feature for car buyers in China.

We define a model by its name, vehicle type, transmission type, and fuel type. Trim level attributes are aggregated to the model level via a simple average, and then matched to our registration data. Price and attributes for each model are constant across all markets in a given year, but exhibit between-year variations due to price updates, introduction of new trims, and withdrawal of old trims. To construct a measure of fuel economy, we first collect information on the fuel consumption per $100 \mathrm{~km}$ for each model from the Ministry of Information and Industrial Technology (MIIT). Then we multiply it with the province-year gasoline price to obtain the average fuel cost in yuan per $100 \mathrm{~km}$.

Besides prices and attributes, another important factor for auto demand is the dealer network. Due to the lack of historical data, we use a cross section of dealer counts by brand and province in March 2016 to approximate the dealership network during our sample period. Appendix A shows that automakers have a more extensive dealer network in their home market than in other provinces, but the differences are not as large as those observed in sales, suggesting that dealer network only

\footnotetext{
${ }^{12}$ We collect the promotion data from Autohome.com, a major privately-run gateway website that regularly updates information on car features and industry headlines. Minimum Retail Price Maintenance (RPM) whereby automakers prohibit dealers from selling below a preset price was common in China in our sample period. For example, the China Automobile Dealers Association complained in 2011 that large automakers imposed RPM and exclusive territory to reduce price-competition among dealers. This did not draw attention from China's antitrust authority until very recently. As in the U.S., RPM is not treated as per se illegal by China's antitrust authority and each case has to be judged based on individual merits.

${ }^{13}$ Consumption tax is levied to promote sales of small and fuel-efficient vehicles. It varies from $1 \%$ to $40 \%$, depending on vehicle size.
} 
partially explains the home bias in sales. In addition, the dealer network itself could be affected by local protective policies.

Information on headquarter and plant locations is obtained from each firm's website. Our final sample consists of 38 domestic firms (6 private firms, $20 \mathrm{JVs}$, and 12 SOEs) and 14 foreign firms. No firm moved its headquarter within our sample period, and only two opened new plants. For each model produced by a domestic firm, we calculate the distance between its plant location and each of its destination markets.

Our raw dataset contains a total of 683 models. Some of them are only sold in a few provinces with low sales. We keep the most popular models that account for $95 \%$ of national sales in each year. Doing so has several benefits. First, sales of small brands are likely measured with errors. Second, and more importantly, since we focus on analyzing differences between vehicle models' local shares and national shares, limiting to major national brands gives us a conservative measure of local protectionism. For example, some brands might not be marketed nationally. Including them in our analysis would exaggerate the extent of local protection. Third, obtaining counterfactual equilibrium prices is computationally challenging when we have a demand system with a large number of products. We drop models priced above 800,000 RMB (about \$123,000), as demand for these luxury brands is likely driven by conspicuous consumption or factors not captured in our stylized model. That leaves us with a total of 179, 218, and 234 models in each year. Choice sets across provinces in any given year do not vary much. For example, in 2011, 25 out of 31 provinces have all 234 models. The choice set does exhibit variation over time, due to entry and exit of vehicle models. The total number of observations is 885,736 at the county-model-year level and 19,505 at the province-model-year level.

Table 2 reports the summary statistics. The average price of a vehicle is 184,700 Yuan (about $\$ 28,000)$. The average price is similar to that observed in the U.S. market but the price range is larger in China. The indigenous brands from domestic automakers tend to occupy the low-end segment while the JVs and imports compete in the high-end segment.

Table 3 below shows that different types of firms have different product mix. JV brands on average have a higher price, a bigger vehicle size, and a more powerful engine compared to private or SOE brands. In addition, JVs have a more extensive dealer network, and a larger fraction of their products have automatic transmission. The price difference between JV products and their domestic counterparts is much larger than the difference in the observed attributes. Higher prices are largely driven by better brand recognition and higher unobserved qualities, which we capture using brand fixed effects in our estimation. Imported products are typically luxury brands, and the majority of them are SUVs.

Rising household income is perhaps the most important factor that drives China's exponential growth in vehicle sales since the mid 2000s. To account for the impact of income on vehicle 
Table 2: Summary Statistics of Key Variables

\begin{tabular}{lrrrr}
\hline Variable & Mean & Std. Dev. & Min & Max \\
\hline Sales & 1259 & 2263 & 1 & 60612 \\
Real price $(1000$ yuan $)$ & 184.7 & 144.5 & 27.5 & 798.7 \\
Fuel cost (yuan/100 km) & 50.1 & 10.0 & 24.9 & 101.2 \\
Engine size (liter) & 1.8 & 0.5 & 0.8 & 4.0 \\
Vehicle size $\left(\mathrm{m}^{2}\right)$ & 7.7 & 0.9 & 4.2 & 10.3 \\
Auto transmission & 0.48 & 0.50 & 0 & 1 \\
SUV & 0.17 & 0.37 & 0 & 1 \\
MPV & 0.06 & 0.24 & 0 & 1 \\
Number of dealers & 20.8 & 23.3 & 0 & 137 \\
Distance to headquarter $(1000 \mathrm{~km})$ & 2.1 & 1.4 & 0 & 5.2 \\
\hline
\end{tabular}

Note: The number of province-model-year observations is 19,505. Sales are annual sales by model and province. The number of dealers is by province and brand.

Table 3: Mean values of Key Variables by Firm Type

\begin{tabular}{lrrrr}
\hline Variable & Private & JV & SOE & Imports \\
\hline Sales & 1289 & 1478 & 1057 & 382 \\
Real price (1000 yuan) & 81.0 & 189.7 & 102.2 & 428.1 \\
Fuel cost (yuan/100 km) & 45.9 & 49.6 & 48.2 & 61.7 \\
Engine size (liter) & 1.6 & 1.8 & 1.6 & 2.5 \\
Vehicle size (m²) & 7.2 & 7.8 & 7.4 & 8.3 \\
Auto transmission & 0.06 & 0.55 & 0.22 & 1 \\
SUV & 0.21 & 0.12 & 0.09 & 0.56 \\
MPV & 0 & 0.04 & 0.13 & 0.11 \\
Number of dealers & 13.5 & 24.6 & 10.0 & 12.0 \\
Number of observations & 2168 & 11444 & 3888 & 2005 \\
\hline
\end{tabular}

Note: Sales are annual sales by province. The number of dealers is by province by brand.

demand, we obtain empirical distributions of household income at the province level from China's $1 \%$ population survey in 2005 , separately for urban and rural households. Such comprehensive data at the individual level or county level for recent years are difficult to find. Consequently, for each year in our sample period, we scale each provincial income distribution from the 2005 survey such that its mean matches the provincial average from the annual China Statistical Yearbooks. ${ }^{14}$ Our implicit assumption is that the shape of income distributions in China did not change significantly between 2005 and 2011.

Besides the income distribution for the general population, we also obtain the income distributions for new vehicle buyers from an annual survey conducted by Ford Motor. ${ }^{15}$ The survey

\footnotetext{
${ }^{14}$ In 2010, the average household income in China is about one seventh of that in the U.S..

${ }^{15}$ The survey covers $20.5 \mathrm{k}, 23.9 \mathrm{k}$, and $34 \mathrm{k}$ vehicle buyers in 2009,2010 , and 2011 , respectively.
} 
Table 4: Micro-moments: Fraction of Vehicle Buyers by Annual Income

(a) Fraction of Households by Annual Income (yuan)

\begin{tabular}{|c|c|c|c|c|}
\hline Year & $<48 \mathrm{k}$ & $48 \mathrm{k}-96 \mathrm{k}$ & $96 \mathrm{k}-144 \mathrm{k}$ & $\geq 144 \mathrm{k}$ \\
\hline \multicolumn{5}{|c|}{ Among Vehicle Buyers } \\
\hline 2009 & 0.16 & 0.34 & 0.32 & 0.19 \\
\hline 2010 & 0.11 & 0.27 & 0.32 & 0.30 \\
\hline 2011 & 0.09 & 0.26 & 0.34 & 0.31 \\
\hline \multicolumn{5}{|c|}{ Among All Households } \\
\hline 2009 & 0.69 & 0.23 & 0.05 & 0.03 \\
\hline 2010 & 0.63 & 0.27 & 0.06 & 0.04 \\
\hline 2011 & 0.55 & 0.33 & 0.08 & 0.04 \\
\hline
\end{tabular}

(b) Fraction of Buyers by Income Brackets for Different Vehicle Segments, 2011

\begin{tabular}{lllll}
\hline \hline Segment & $<48 \mathrm{k}$ & $48 \mathrm{k}-96 \mathrm{k}$ & $96 \mathrm{k}-144 \mathrm{k}$ & $\geq 144 \mathrm{k}$ \\
\hline Small/mini sedan & 0.15 & 0.40 & 0.30 & 0.15 \\
Compact sedan & 0.11 & 0.30 & 0.37 & 0.22 \\
Medium/large sedan & 0.05 & 0.16 & 0.32 & 0.47 \\
SUV & 0.05 & 0.15 & 0.33 & 0.47 \\
MPV & 0.07 & 0.24 & 0.33 & 0.36 \\
\hline \hline
\end{tabular}

breaks annual household income into four brackets: less than 48k Yuan, 48k-96k Yuan, 96k-144k Yuan, and greater than or equal to $144 \mathrm{k}$ Yuan, and reports the fraction of vehicle buyers from each income bracket in each year. It further divides vehicles into 24 types and reports the fraction of car buyers in each income bracket for each vehicle type. We aggregate the 24 types into five segments: mini/small sedan, compact sedan, medium/large sedan, sport utility vehicle (SUV), and multi-purpose vehicle (MPV).

The first panel of Table 4 compares the income distribution among all vehicle buyers to that of the general population. The second panel of Table 4 reports consumers' income distribution for each of the five vehicle segments in 2011. Consumers with a higher household income are disproportionately more likely to buy new vehicles, especially high-end sedans, SUVs, and MPVs. In 2011, only $4 \%$ of Chinese households have annual income above 144k (the median car price in our sample), yet they account for $47 \%$ of the sales of medium/large sedans and SUVs, and $36 \%$ of MPVs. The information on income distribution is used to form micro-moments in our estimation as in Petrin (2002) and helps us to separately identify price elasticity and income elasticity. 


\section{Descriptive Evidence}

Figure 2: Home-province and national market shares

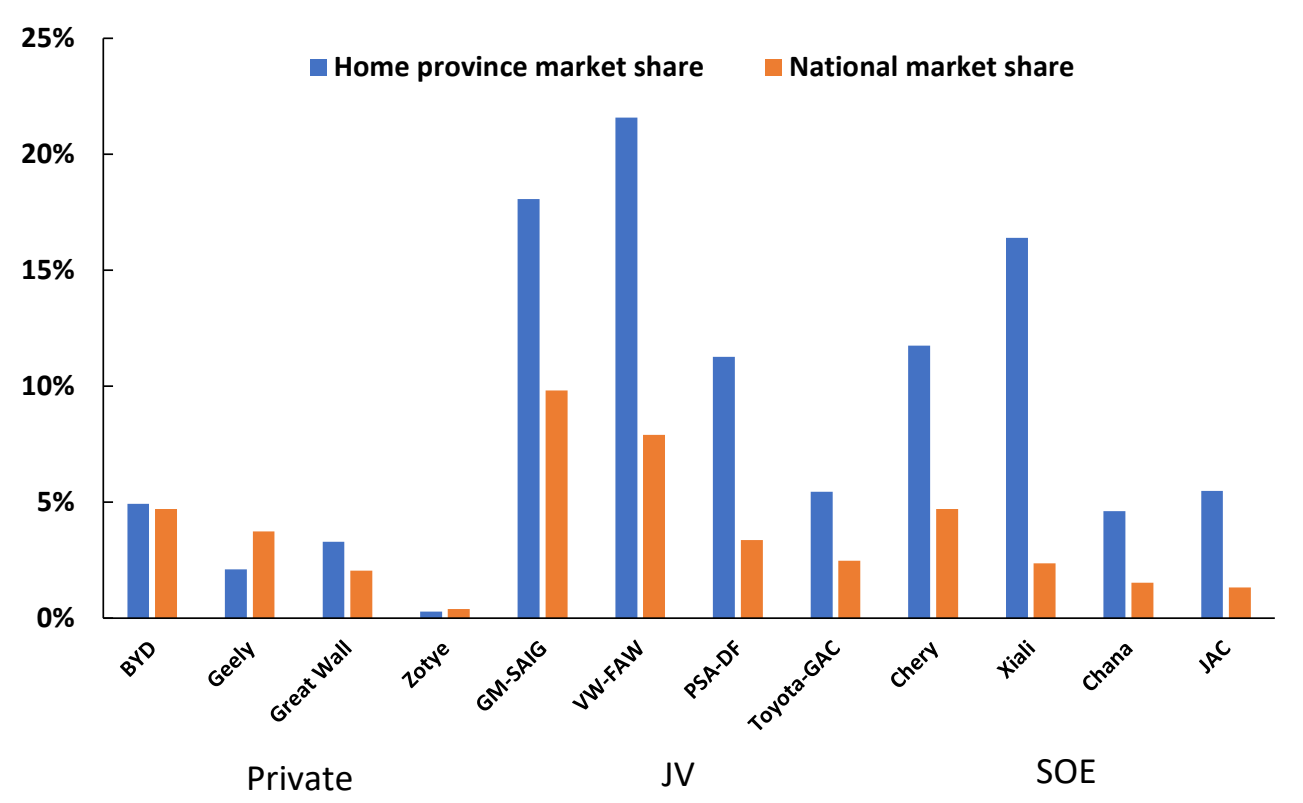

We first provide descriptive evidence on the strong home bias enjoyed by JVs and especially SOEs. To graphically illustrate this, we compare the market share at the national level with that in the headquarter province for the largest automakers in Figure 2. The firms are grouped by their ownership types: the first four are private automakers, the next four JVs, and the last four SOEs ${ }^{16}$. For non-private firms, especially SOEs, market shares in their local markets are significantly higher than those at the national level. One notable example is Xiali: it accounts for only $2.4 \%$ of national new vehicle sales but enjoys a market share of $16.4 \%$ in its home province Tianjin. The median 'local-to-national' ratio of market shares is 3.36 for SOEs and 1.88 for JVs. Interestingly, there is no noticeable home bias for most private automakers. Appendix A documents the patterns of home bias for all 38 automakers in our sample: across the board, SOEs exhibit the strongest home bias and private automakers the least.

The pattern of home bias is stronger among institutional purchases. Appendix A lists the local market share and national market share by each firm separately for individual purchases and institutional purchases. Strong home bias for institutional purchases is perhaps not surprising: they are mostly under the discretion of the local governments, hence there is likely a high level of government favouritism for local firms. Interestingly, there is a strong positive correlation of 0.64

\footnotetext{
${ }^{16}$ For each firm type, we select firms that have the largest national market shares. These twelve firms together account for $54.9 \%$ of total vehicle sales in China between 2009 and 2011.
} 
between home biases in individual purchases and government procurement, as shown in Figure 3. This provides suggestive evidence that government protection could also be an important factor in the private car market.

Figure 3: Home biases in individual and institutional purchases

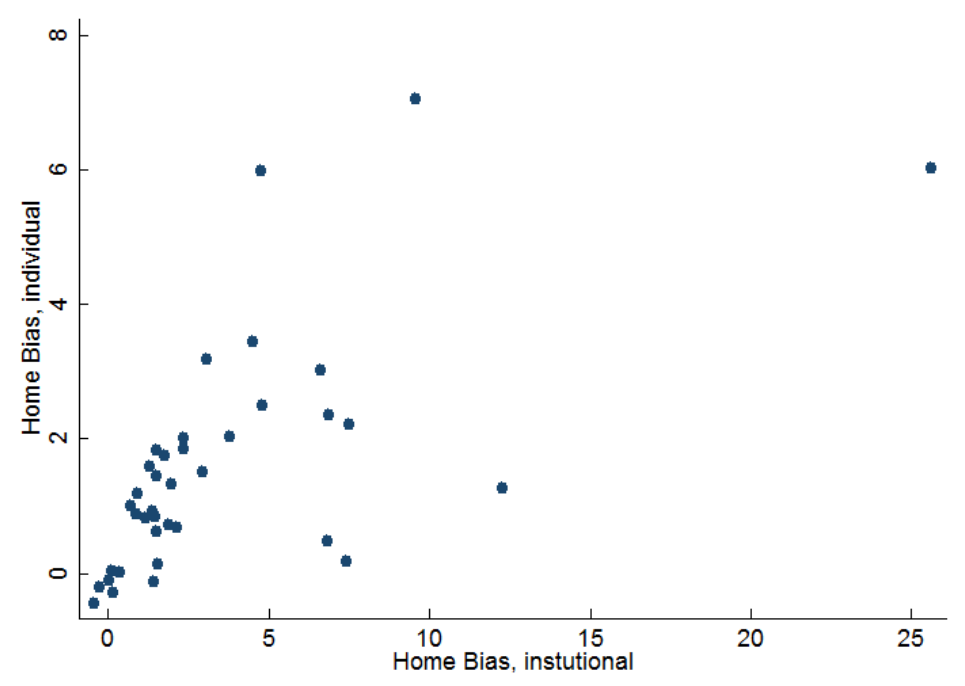

Notes: We define home bias the the ratio between home market share and national share minus one.

Besides local protectionism, there are a number of potential explanations for the home bias. First, transportation cost is lower for cars assembled locally. But the logistic network is now very well developed and the transportation cost of a car is on average only 1000 yuan, less than one percent of vehicle prices for most models. A vehicle's price (MSRP) is the same nationwide and our promotion data do not show appreciable differences between local and non-local products. Nonetheless, distance affects the speed of delivery and could be correlated with the extent of consumers' exposure to product information and local advertising. In our spatial RD analysis, we focus on counties that border with each other and hence have similar distances to the production facilities. In the structural analysis in Section 5, we control for the distance between the production location and the destination market.

Second, auto firms are more likely to have an extensive dealer network in their headquarter province. We control for the number of dealers by either focusing on adjacent counties or including it in the regression explicitly. It is worth noting that the observed differences in dealer network could be partly driven by policies that favor local brands in the process of issuing dealer license permits.

Third, firms might specialise in products that cater to the need and taste of local consumers. For example, many JVs have headquarters in high-income markets such as Beijing, Shanghai, and 
Guangdong, and sell high-end brands that are popular among wealthy households. Similarly, SOEs that produce cheap indigenous brands tend to locate in less wealthy provinces such as Anhui, Jilin, and Liaoning. The better match between household income and the market segment could lead to larger market shares locally than nationally for these products, as documented in Cosar et al. (2016). We conduct falsification tests to examine this directly.

Fourth, to the extent that SOEs or JVs are more likely to advertise locally, our home bias could simply reflect demand responses to heterogeneous marketing strategies. Finally, preference for locally produced vehicles could arise from consumer ethnocentrism whereby purchasing products from certain groups is viewed as inappropriate because doing so hurts local economy (Shimp and Sharma, 1987). It is important to note that consumer sentiments such as ethnocentrism often arise in the context of products from different sovereign countries (Klein and Ettensoe, 1999; Canli and Maheswaran, 2000), while our research focuses on interregional trade within China.

In the next section, we evaluate each of these alternative explanations in details using our county-level vehicle sales data.

\section{Spatial Regression Discontinuity and Falsification Tests}

In this section, we use a spatial regression discontinuity analysis and a series of falsification tests to rule out alternative explanations and establish local protectionism as the leading cause of home bias.

\subsection{Spatial Regression Discontinuity}

Our first analysis employs a spatial discontinuity design using adjacent counties across provincial borders. We focus on provinces that have local automakers and group counties into clusters of two or three adjacent counties on different sides of a provincial border. We leave out counties along the borders of Tibet, Xinjiang, and Qinghai, which are too large and more likely to have idiosyncratic characteristics. Our sample consists of 630 counties in 285 clusters as shown in different color in Figure 4.

The spatial discontinuity design takes advantage of the fact that provincial borders lead to discontinuity in the types of protective policies discussed in Section 2.1, while assuming similar consumer preference across the borders. The key empirical pattern of interest is whether the differences in market shares persist within each cluster, that is, whether brands sell much better in a county within the home province than in the nearby county across the border. The underlying assumption is that because of the geographic proximity, consumers within a cluster have similar 
Figure 4: Clusters of Counties along Provincial Borders

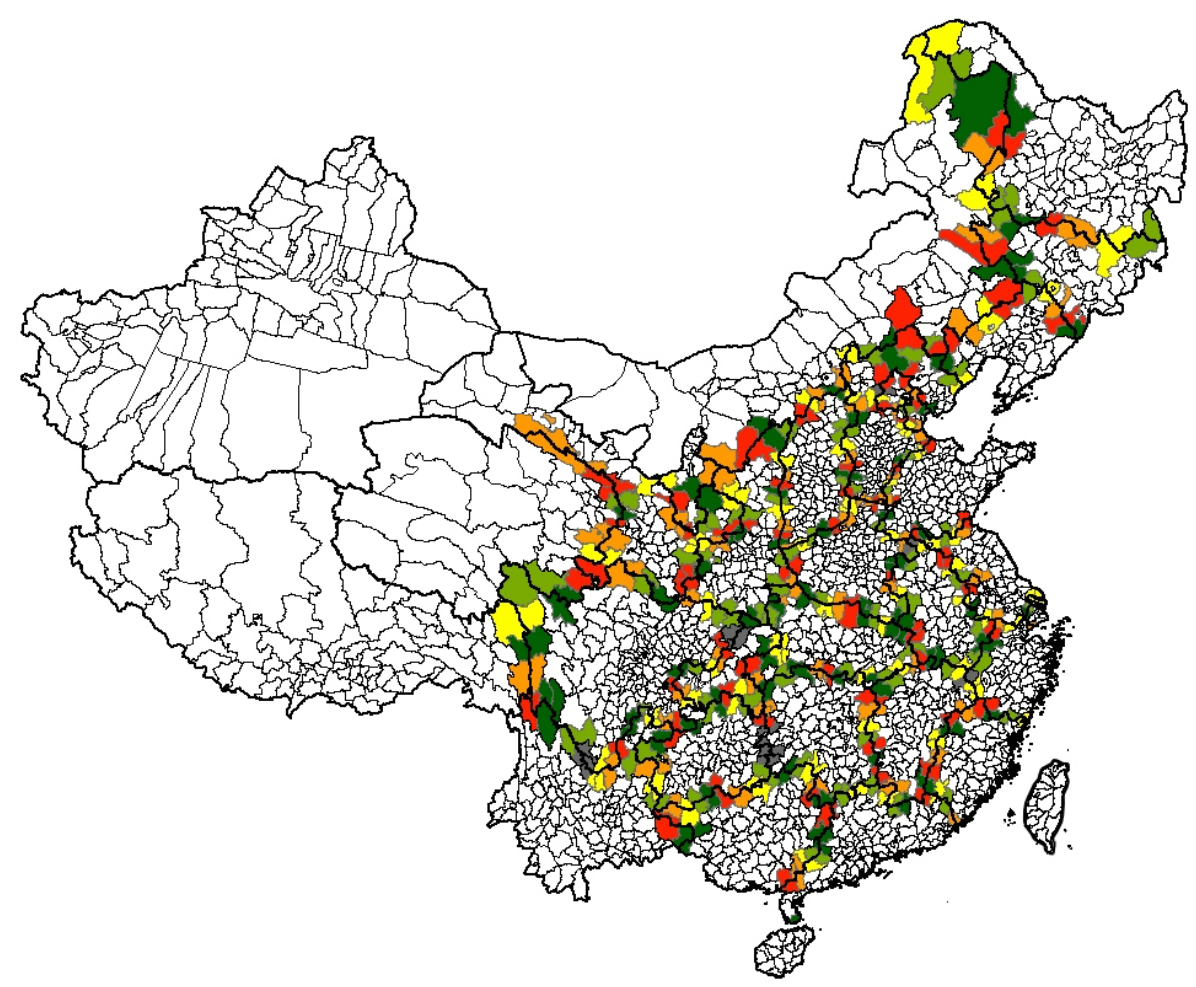

access to product information and dealer stores ${ }^{17}$, as well as similar taste for vehicles.

We cannot conduct a standard 'balance test' since the 'treatment status' (whether a county is the home market to a product) differs across different car models for the same county. In Table 5, we document the mean and standard deviation of several demographic attributes for two random counties from all counties in the country (column 1), two counties from a random cluster (column 2), and two counties from a sub-sample of clusters that have smaller intra-cluster dispersion in GDP per capita. ${ }^{18}$

Table 5 shows that consumer demographic differences across counties within a cluster in our regression sample are substantially smaller than the differences between two random counties, especially for the set of clusters that are more homogeneous. For example, the average ratio of GDP per capita is 2.07 between two random counties, but is 1.62 between two counties in the same cluster, and further declines to 1.26 in column 3. The dispersion measured by standard deviation

\footnotetext{
${ }^{17}$ When one buys a car from a dealer in another county, the registration will occur at the county of residence and is recorded so in our data. Arbitrage - buying in places with subsidy and selling elsewhere - is uncommon. To the extent that it exists, our subsidy estimates will be conservative since arbitrage reduces the sales disparity between regions with subsidies and regions without.

${ }^{18}$ We draw 500 random pairs of counties for each column. Data on GDP per capita is available for 2039 our of 2236 counties, while data on average urban and rural household incomes are available for 1811 out of 2336 counties. For each variable, we draw among counties with non-missing values. In column 3 of Table 5, we draw from a sub-sample of clusters where the ratio between the highest and lowest GDP per capita is less than 1.6.
} 
also shrinks considerably as we move across columns: from 2.63 in column 1 to 0.25 in column 3 .

Table 5: Median differences in consumer demographics between different counties

\begin{tabular}{|c|c|c|c|}
\hline Variable & Two random counties & Same cluster & $\begin{array}{r}\text { Same cluster, } \\
\text { GDP ratio }<1.6\end{array}$ \\
\hline \multirow[t]{2}{*}{ Ratio in GDP per capita } & 2.07 & 1.62 & 1.26 \\
\hline & $(2.63)$ & $(1.32)$ & $(0.25)$ \\
\hline \multirow[t]{2}{*}{ Ratio in mean urban household income } & 1.22 & 1.20 & 1.19 \\
\hline & $(0.29)$ & $(0.21)$ & $(0.22)$ \\
\hline \multirow[t]{2}{*}{ Ratio in mean rural household income } & 1.47 & 1.32 & 1.22 \\
\hline & $(0.78)$ & $(0.46)$ & $(0.29)$ \\
\hline \multirow[t]{2}{*}{ Difference in mean age } & 0.43 & 0.32 & 0.30 \\
\hline & $(1.02)$ & $(0.39)$ & $(0.31)$ \\
\hline \multirow[t]{2}{*}{ Difference in percentage male $(\%)$} & 2.48 & 1.63 & 1.48 \\
\hline & $(3.66)$ & $(2.42)$ & $(2.44)$ \\
\hline
\end{tabular}

Notes: Standard deviations of the ratios or differences over 500 draws are reported in brackets. Data on GDP per capita, and mean urban and rural household incomes come from China Statistical Yearbooks. Mean age and gender ratio are calculated using individual car buyer information from our vehicle registration records.

We implement the spatial discontinuity design in the logit framework following Berry (1994):

$$
\begin{aligned}
\ln \left(\frac{s_{j m}}{s_{0 m}}\right)= & \beta_{1} \mathrm{HQ}_{j m} \mathrm{PRI}_{j}+\beta_{2} \mathrm{HQ}_{j m} \mathrm{JV}_{j}+\beta_{3} \mathrm{HQ}_{j m} \mathrm{SOE}_{j} \\
& +\gamma_{1} \mathrm{PL}_{j m} \mathrm{PRI}_{j}+\gamma_{2} \mathrm{PL}_{j m} \mathrm{JV}_{j}+\gamma_{3} \mathrm{PL}_{j m} \mathrm{SOE}_{j} \\
& +\phi_{j c(m)}+\delta_{m}+\eta_{t}+\xi_{j m t}
\end{aligned}
$$

where $s_{j m}$ stands for the market share of product $j$ in county $m$, and $s_{0 m}$ stands for the share of the outside option. $H Q_{j m}$ is the local product dummy and $P R I_{j}, J V_{j}, S O E_{j}$ are dummies for products that are produced by a private firm, a JV, and an SOE, respectively. While our main focus is the impact on sales in the headquarter province, we also control for the presence of assembly plants. $P L_{j m}$ takes value 1 in all counties in a province that produces model $j$ but is not the headquarter province.

Importantly, cluster-by-model fixed effects, $\phi_{j c(m)}$, control for cluster-specific preferences for different brands, e.g., one cluster may prefer SUVs over sedans due to road conditions. After further controlling for county fixed effects and year fixed effects, we identify our parameters of interest, $\beta_{1}$ to $\beta_{3}$, from the difference in market shares between a county in the home province and counties across the border within the same clusters, separately for each firm type.

In the standard RD design, one would include a running variable such as the distance from the provincial boarder to capture other potential confounding factors that could change continuously with distance. Since we focus on counties on the boarders, results are essentially the same with or without the distance-to-production variable. Demographic variables (income, age structure, family 
size, etc.) are absorbed by county and year fixed effects.

Table 6 summarizes the results. All columns include county fixed effects and year fixed effects. In columns (1) and (2), we control for model fixed effects. Column (1) includes all 2336 counties in our full sample, while column (2) only includes the 630 counties along provincial borders. Results in columns (1) and (2) are similar, indicating that the magnitude of home bias does not differ significantly between the full sample and the subsample of counties along provincial boarders. ${ }^{19}$ From column (3) on, we implement the spatial discontinuity design by including cluster-model fixed effects. The estimates of $\beta_{2}$ and $\beta_{3}$ capture home bias: sales for JVs and SOEs in their home markets are higher by $82 \%$ and $180 \%$, respectively. We do not find any evidence for home bias for private products across all RD specifications. Home bias for JVs and SOEs decreases moderately between columns (2) and (3): down from $82 \%$ to $52 \%$ for JVs and from $180 \%$ to $159 \%$ for SOEs. Column (4) restricts the sample to clusters where the ratio between the highest and lowest GDP per capital across counties is less than 1.6. There are 321 counties in these clusters. Reassuringly, results in columns (3) and (4) are similar.

Some counties have auto assembly plants. Discount programs that provide strong incentives for employees to buy cars from their own firms could contribute to home bias. Column (5) further drops clusters with production counties. Results stay unchanged from column (4), confirming that our finding is not driven by employee discount. There are 79 assembly plants in our full sample, 19 of which are located outside the headquarter provinces. Our results also show that SOEs, but not JVs or private automakers, enjoy higher demand in non-local markets where they have production facilities.

In conclusion, the large $\beta$ estimates that survive cluster-model fixed effects and various controls suggest that distance, access to dealers, consumer demographics, and employee discounts are unlikely to be drivers of home bias observed in our data.

\subsection{Alternative Explanations}

The key identification assumption of our RD analysis is that there is no discontinuity in demand or supply factors across provincial boundaries. This could be violated for a number of reasons such as a better match between product attributes and consumer preference locally or discontinuity in demand preference along the border, local advertising, and consumer ethnocentrism. We now examine each of these potential treats in turn.

\footnotetext{
${ }^{19}$ In column (1), $\hat{\beta}_{1}$ is negative and statistically significant, implying that private brands fare worse in their home markets. Private firms are often based in wealthy provinces (e.g. Zhejiang, Guangdong, Shandong) where consumers are less likely to buy low-end private brands. After we restrict the sample to clusters on provincial borders in column (2) and implement the RD design from column (3) onwards, $\hat{\beta}_{1}$ becomes statistically insignificant.
} 
Table 6: Results from the spatial discontinuity model

\begin{tabular}{|c|c|c|c|c|c|}
\hline & All counties & Clusters & Clusters & Clusters & $\overline{\text { Clusters }}$ \\
\hline & & & & GDP ratio $<1.6$ & GDP ratio $<1.6$ \\
\hline & (1) & (2) & (3) & (4) & (5) \\
\hline \multirow[t]{2}{*}{$\mathrm{HQ}^{*}$ Private, $\beta_{1}$} & $-0.35 * * *$ & -0.15 & 0.10 & 0.01 & 0.01 \\
\hline & $(0.03)$ & $(0.11)$ & $(0.11)$ & $(0.12)$ & $(0.12)$ \\
\hline \multirow[t]{2}{*}{$\mathrm{HQ}^{* J V}, \beta_{2}$} & $0.68 * * *$ & $0.60 * * *$ & $0.42 * *$ & $0.40 * * *$ & $0.40 * * *$ \\
\hline & $(0.05)$ & $(0.05)$ & $(0.04)$ & $(0.05)$ & $(0.05)$ \\
\hline \multirow[t]{2}{*}{$\mathrm{HQ} * \mathrm{SOE}, \beta_{3}$} & $1.09 * * *$ & $1.03 * * *$ & $0.95 * * *$ & $0.87 * * *$ & $0.87 * *$ \\
\hline & $(0.03)$ & $(0.06)$ & $(0.06)$ & $(0.10)$ & $(0.10)$ \\
\hline \multirow[t]{2}{*}{ PL $*$ Private, $\gamma_{1}$} & $0.26 * * *$ & $0.21 * * *$ & 0.15 & -0.08 & -0.09 \\
\hline & $(0.03)$ & $(0.06)$ & $(0.09)$ & $(0.19)$ & $(0.19)$ \\
\hline \multirow[t]{2}{*}{$\mathrm{PL} * J V, \gamma_{2}$} & $0.15 * * *$ & $0.18 * * *$ & 0.03 & -0.10 & -0.10 \\
\hline & $(0.01)$ & $(0.04)$ & $(0.07)$ & $(0.09)$ & $(0.09)$ \\
\hline \multirow[t]{2}{*}{ PL*SOE, $\gamma_{3}$} & $0.63 * * *$ & $0.61 * * *$ & $0.43 * * *$ & $0.67 * * *$ & $0.67 * * *$ \\
\hline & $(0.04)$ & $(0.08)$ & $(0.12)$ & $(0.16)$ & $(0.16)$ \\
\hline Model FE & Yes & Yes & No & No & No \\
\hline Cluster-model FE & No & No & Yes & Yes & Yes \\
\hline No. of counties & 2336 & 630 & 630 & 321 & 319 \\
\hline No. of obs. & 885,376 & 180,398 & 180,398 & 77,039 & 76,751 \\
\hline
\end{tabular}

Notes: The dependent variable is $\ln \left(\frac{s_{j m}}{s_{0 m}}\right)$. All regressions include county fixed effects and year fixed effects. Column (1) uses all counties. Columns (2) and (3) use the 630 counties along provincial boarders that we group into clusters. Column (4) restricts to clusters within which the ratio between the highest and lowest GDP per capita across counties is less than 1.6. Column (5) further drops all production counties from the sample. $\mathrm{p}<0.1, * * \mathrm{p}<0.05, * * * \mathrm{p}<0.01$. Standard errors are clustered at the cluster level.

\subsubsection{Falsification Tests}

If home bias arises because local products have attributes that better cater to the needs and tastes of local consumers, then we should expect a spike in sales for non-local products that are similar to the local products. In our first falsification test, we replace each local model with its closest nonlocal counterpart(s). Specifically, we divide models in our sample to 242 groups that have similar attributes but different and non-adjacent headquarter provinces in each year. Models in each group are made by the same type of firm, and fall in the same vehicle segment or adjacent segments. In addition, we match them on price, fuel economy, engine size, and vehicle size. ${ }^{20}$ For example, Civic produced by Dongfeng-Honda (based in Hubei province) is matched with Corolla produced by FAW-Toyota (based in Tianjin).

We switch headquarters between models in each of the 242 groups (for example, DongfengHonda Civic is assigned to Tianjin while FAW-Toyota Corolla is assigned to Hubei) and repeat the regression discontinuity analysis as in section 4 . Results are reported in Table 7 . The coefficients

\footnotetext{
${ }^{20}$ Matching by attributes is sometimes subjective. Nonetheless, the choices are mostly obvious as competing products in the same or adjacent segments usually have similar attributes. The median price range in a group is 5000 yuan.
} 
of fake local status for JV and SOE products are negative and significant in column (1) and (2), and small and statistically insignificant under the RD design in columns (3) and (4). Although consumer prefer local JVs and SOEs as shown in section 4, they do not prefer close substitutes that are non-local. We conclude that the home bias is unlikely to be driven by better compatibility between consumer demographics and local product attributes.

Table 7: Results from falsification test with placebo headquarters

\begin{tabular}{lrrrrr}
\hline \hline & All counties & Clusters & Clusters & $\begin{array}{r}\text { Clusters } \\
\text { GDP ratio }<1.6\end{array}$ & $\begin{array}{r}\text { Clusters } \\
\text { GDP ratio }<1.6\end{array}$ \\
& $(1)$ & $(2)$ & $(3)$ & $(4)$ & $(5)$ \\
\hline FakeHQ*Private, $\theta_{1}$ & $-0.11^{* * *}$ & -0.02 & 0.13 & 0.05 & 0.05 \\
& $(0.03)$ & $(0.06)$ & $(0.07)$ & $(0.08)$ & $(0.08)$ \\
FakeHQ*JV, $\theta_{2}$ & $-0.04 * * *$ & $-0.05^{* * *}$ & -0.03 & 0.01 & 0.01 \\
& $(0.01)$ & $(0.02)$ & $(0.02)$ & $(0.03)$ & $(0.03)$ \\
FakeHQ*SOE, $\theta_{3}$ & $-0.26^{* * *}$ & $-0.31^{* * *}$ & -0.04 & -0.09 & -0.09 \\
& $(0.02)$ & $(0.05)$ & $(0.05)$ & $(0.08)$ & $(0.08)$ \\
Model FE & Yes & Yes & No & No & No \\
Cluster-model FE & No & No & Yes & Yes & Yes \\
No. of counties & 2336 & 630 & 630 & 321 & 319 \\
No. of obs. & 885,376 & 180,398 & 180,398 & 77,309 & 76,751 \\
\hline \hline
\end{tabular}

Notes: The dependent variable is $\ln \left(\frac{s_{j m}}{s_{0 m}}\right)$. All regressions include county fixed effects and year fixed effects. Column (1) uses all counties. Columns (2) and (3) use the 630 counties along provincial boarders that we group into clusters. Column (4) restricts to clusters within which the ratio between the highest and lowest GDP per capita across counties is less than 1.6. Column (5) further drops all production counties from the sample. $\mathrm{p}<0.1,{ }^{* *} \mathrm{p}<0.05, * * * \mathrm{p}<0.01$. Standard errors are clustered at the cluster level.

To further examine the extent of consumer preference heterogeneity among neighboring counties across provincial borders, we turn to provinces that don't have any auto firm headquarters. ${ }^{21}$ We generate 93 county clusters from these provinces following the same procedure as in Section 4. For each cluster, we arbitrarily specify one county as the treatment group and estimate equation (1) cluster by cluster, focusing on the interactions between each ownership type and the treatmentcounty dummy. In sharp contrast to results documented in section 4 , here we find no strong evidence that consumers favor either group of products. The coefficient estimate for the interaction between SOE (JV) products and the treatment county, either positive or negative, is significant at the $5 \%$ level for only $5(10)$ out of 93 clusters. ${ }^{22}$ While this might constitute as statistical evidence against the null of homogeneous preference among counties in these clusters, the limited response here is unlikely to explain most of the home bias patterns documented above.

\footnotetext{
${ }^{21}$ There are 31 provinces in China. Twenty provinces have auto headquarters. We use the remaining eleven provinces in our falsification tests, including two provinces that have auto assembly plants but no headquarters.

${ }^{22}$ County fixed effects are excluded in these regressions, since they are perfectly colinear with the treatment status. Some of the significant coefficients could be driven by county fixed effects.
} 


\subsubsection{Local TV Advertising}

Advertising on local TV channels whose coverage stops at the provincial borders is another potential confounding factor that could shape vehicle demand and create discontinuity at the boarder. The validity of this argument rests on three conditions. First, TV advertising should be an important source of information that affects consumer vehicle purchase decisions. Second, local TV channels account for a non-trivial market share of national viewership. Third, SOEs and JVs advertise more heavily on local channels than private automakers.

To examine the importance of TV advertising, we use a national survey by China's National Information Center in 2012 that covers 6,634 vehicle owners from all major cities in China. Respondents are asked to choose information channels that have influenced their vehicle purchase decisions. As shown in figure 4, word-of-mouth from friends and relatives is by far the most important information source and is chosen by $75 \%$ of respondents. In comparison, only $12 \%$ of respondents choose TV advertising as a source of information. While $29 \%$ of respondents consider word-of-mouth as the most influencing channel, only $2.1 \%$ consider TV advertising as the most influencing source in their purchase decisions.

Figure 5: Sources of information influencing purchase decisions

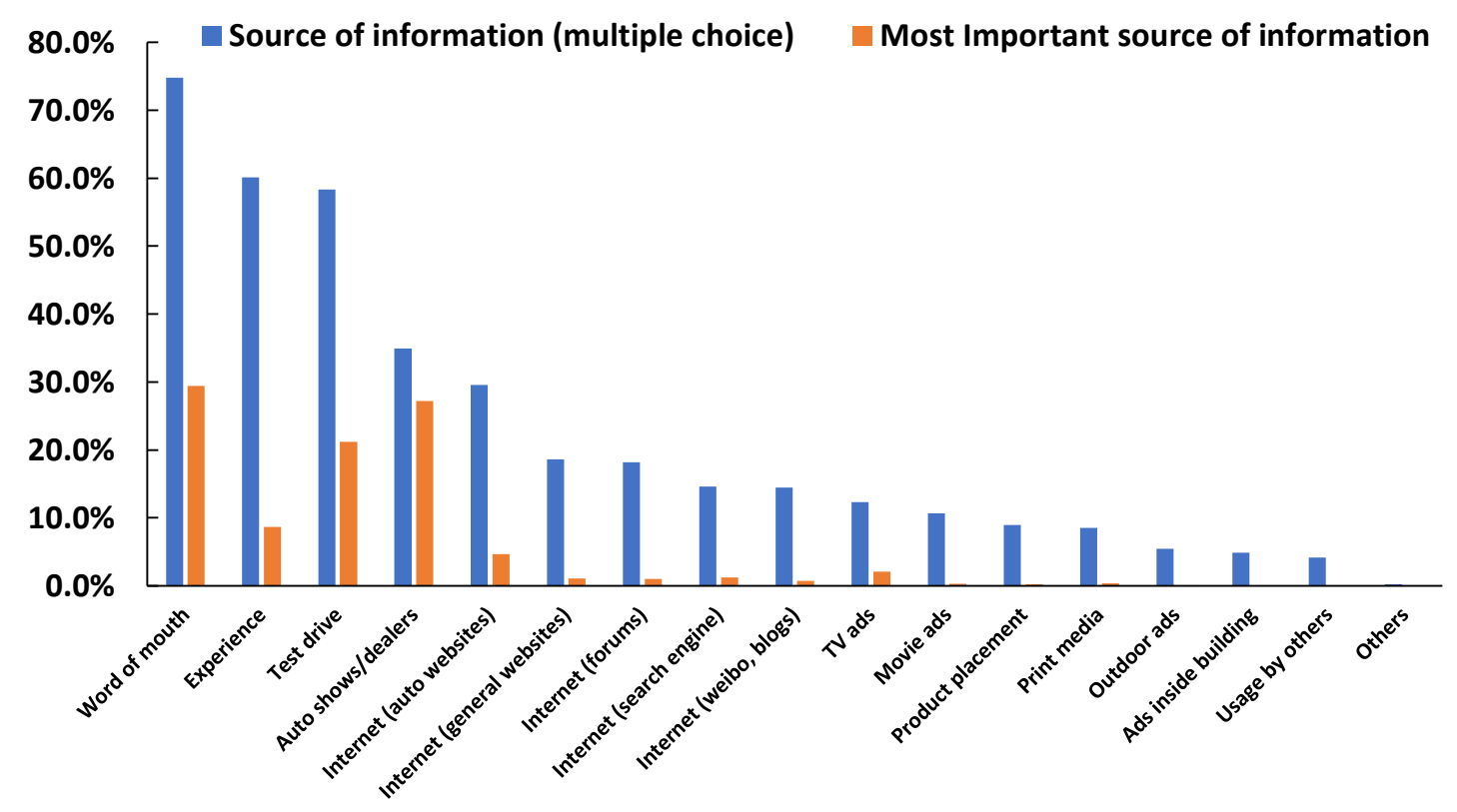

There are three types of TV channels in China: national channels that have national coverage; provincial channels (satellite and non-satellite) that could have national or provincial coverage; prefecture/county-level (local) TV channels that mainly serve local audiences ${ }^{23}$ In 2010 , local TV

${ }^{23}$ From 2011 China TV Rating Yearbook, there were 247 TV stations and about 3000 channels in China. On average,
each household had access to 41 channels. About $71 \%$ of urban households and $40 \%$ of rural households had access 
channels accounted for less than $20 \%$ of national TV viewership.

Compared to their counterparts in the U.S. or Europe, Chinese auto makers spend a small fraction of revenue on advertising, less than 1\% in 2014 (Nielsen-CCData, 2015). We do not have data on advertising spending by local channels vs. national channels for Chinese auto firms. However, given its limited influence on consumer demand and modest share of national viewership, local TV advertising is unlikely to deliver the observed patterns of home bias.

\subsubsection{Consumer Ethnocentrism}

Consumer ethnocentrism, an innate preference for local products, is another potential confounding factor. Our RD analysis shows that private automakers do not have any appreciable advantage in their home markets. For consumer ethnocentrism to be the driver of home bias, one has to argue that this kind of innate preference for local brands only applies to SOEs and JVs but not to private automakers. To directly gauge consumers' awareness of local status and firm ownership structure, we conducted a survey in November 2016 in Chongqing, a large municipality in Southwest China. The survey questionnaire and summary statistics of the survey results are provided in Appendix C.

The survey was conducted in four different dealer stores, where dealer visitors were requested to fill out a simple questionnaire. The survey questions cover two local firms, LiFan (a local private firm) and Chana (a local SOE), in addition to five other major auto firms. There are five questions on firm ownership type, five questions on local status, and five questions on the importance of price, fuel efficiency, engine size, brand reputation, and being a local brand in vehicle purchase decisions. Among 315 surveys, 297 are complete and our analysis are based on these complete responses.

Overall, our survey provides compelling evidence against consumer ethnocentrism as an explanation for home bias. Out of 297 respondents, only 92 (31\%) correctly identify both the ownership type and local status of the two local brands, LiFan and Chana. Among these 92 respondents, 28

mistake some of the non-local brands as local and only one of them could recognize the ownership types of all three non-local brands.

This survey may overestimate consumers' knowledge of the auto industry. First, the survey is conducted in 2016, five years after our sample period. The national sales of automobiles nearly doubled from 2011 to 2016. Our survey respondents are likely to have a better knowledge of the automobile industry than consumers in 2011. Second, Chongqing is one of the four directcontrolled municipalities (equivalent to provinces administratively) together with Beijing, Shanghai and Tianjin. Given its small geographic area relative to a province, Chongqing residents are more likely to be aware of local firms than a typical resident in a province.

Among these 92 respondents who could recognize two local firms, only $23 \%$ consider buying local brands as very important, while 53\% consider it not important at all. That makes it the least to cable TV. 
important of the five factors we cover in the survey: $49 \%$ of the 92 respondents consider price to be very important, followed by engine size (38\%), fuel economy (37\%), and brand reputation (30\%). In terms of how demographics are related to these answers, male, older respondents and those with high school education or less tend to have better knowledge about ownership type and location. Demographics does not seem systematically correlated with the importance of different factors (price, local status, etc.) in vehicle purchase decisions.

These results suggest that most consumers are not well-informed about the location and ownership type of different automakers and even if some do, intrinsic preference for local brands is at most a periphery factor in their purchase decisions.

To summarize, our analysis shows a large home bias among JVs and especially SOEs, but not among private automakers. The evidence provided suggests that the home bias is not driven by transportation costs, sales network, consumer preference heterogeneity, or innate preference for local products. The pattern of home bias is consistent with our discussion in Section 2 that local protective policies tend to be more favorable to JVs and SOEs because of their importance in the local economy and their institutional connection with the local government. Together, these findings point to local protection rather than consumer preferences as the main contributing factor of home bias.

\section{Structural Model of the Automobile Market}

In this section, we first estimate consumer demand for new vehicles, taking into consideration both observed and unobserved consumer heterogeneity. We quantify the magnitude of local protection by estimating firm-type-specific home-market discounts that are consistent the observed home bias. With demand-side estimates, we then back out the cost function assuming optimal pricing under Bertrand-Nash competition. We present the demand and supply models and then discuss identification and estimation strategies.

\subsection{Demand}

We define each province in each year as a separate market. In each market, households choose from $J_{m t}$ models and the outside option to maximize their utility. We define the indirect utility of household $i$ buying product $j$ in market $m$ and year $t$ as a function of products attributes and household demographics:

$$
u_{m t i j}=\bar{u}\left(\left(1-\rho_{m j}\right) \mathrm{p}_{t j}^{0}, \mathrm{X}_{t j}, \xi_{m t j}, \mathrm{D}_{m t i}\right)+\varepsilon_{m t i j},
$$


where $\bar{u}$ denotes the part of utility that is explained by product attributes and consumer demographics, and $\varepsilon_{m t i j}$ is a random taste shock which we assume to follow the type I extreme value distribution. Utility from the outside option is normalized to $\varepsilon_{m t i 0}$.

Given that local protectionism takes many forms, including explicit discounts for local brands and implicit barriers for non-local brands, it is impractical to incorporate formally all different forms of protection into our model. Instead, we capture them by a price discount for local brands. Let $\mathrm{p}_{t j}^{0}$ denote the retail price of product $j$ in year $t$, which is the same nationwide. Price with protection is denoted as

$$
\mathrm{p}_{m t j}=\left(1-\rho_{m j}\right) \mathrm{p}_{t j}^{0},
$$

where $\rho_{m j}$ stands for the discount rate for product $j$ in market $m$. In our baseline model, $\rho_{m j}$ takes one of four values: $\rho_{1}, \rho_{2}, \rho_{3}$ if $j$ is a local private product, a local JV product, or a local SOE product, respectively, and 0 otherwise. We model local protection as a percentage price discount instead of a flat rebate for two reasons. First, there is large dispersion in prices for products under the same firm type. For example, the price range for JVs is 48,655 yuan to 717,757 yuan, and the price range for SOEs is 39,891 yuan to 261,861 yuan. In addition, we observe large home bias for all price levels. Third, when we proxy home bias with the ratio of the home market share over the national market share minus 1 , home bias is uncorrelated with price: the correlation between home bias and price is -0.07 for JV brands, and -0.04 for SOE brand. A flat rebate would generate a negative correlation between home bias and price and smaller home bias for more expensive car models. Furthermore, when we experiment with a flat rebate in our estimation, the model has a difficult time fitting data: flat rebate pushes the effective price of the cheapest local models towards 0 , which make these products popular among poor households in a way that is inconsistent with our micro-moments. Given these considerations, we model local protection as a percentage price discount.

We use $\mathrm{D}_{m t i}$ to denote household attributes and specify $\bar{u}\left(\mathrm{p}_{m t j}, \mathrm{X}_{t j}, \xi_{m t j}, \mathrm{D}_{m t i}\right)$ as

$$
\bar{u}_{m t i j}=-\alpha_{m t i} \mathrm{p}_{m t j}+\sum_{k=1}^{K} \mathrm{X}_{t j k} \tilde{\beta}_{m t i k}+\mathrm{B}_{j}+\zeta_{m}+\eta_{t}+\xi_{j}
$$

Household i's marginal util from a dollar, $\alpha_{m t i}$, is defined as

$$
\alpha_{m t i}=e^{\bar{\alpha}_{m t i}} * y_{m t i}^{\alpha_{1}} * e^{\sigma_{p} v_{m t i}}
$$

which has three components. The first term $e^{\bar{\alpha}_{m t i}}$ reflects the base level of price sensitivity. We allow it to take four different values, one for each of the four income brackets in the Ford survey, to better match our micro-moments. $y_{m t i}$ is household $i$ 's income in year $t$, drawn from market $m$ 's income distribution. The second component $y_{m t i}^{\alpha_{1}}$ captures how household income influences consumer 
sensitivity to price. One would expect $\alpha_{1}$ to be negative since high-income households tend to be less responsive to a price increase due to the diminishing marginal utility of money. While in principle the income power $\alpha_{1}$ is identified, in practice it is difficult to estimate and often delivers extreme elasticities for households with low or high income levels. We follow Berry et al. (1999) and set $\alpha_{1}$ to -1 . Finally, we introduce a random shock $e^{\sigma_{p} v_{m t i}}$ to capture idiosyncratic factors that influence price elasticity, including parental support, inheritance, and assets accumulated in the past. $v_{m t i}$ is assumed to follow the standard normal distribution, and $\sigma_{p}$ is a parameter to be estimated. Both $\mathrm{y}_{m t i}$ and $\mathrm{p}_{m t j}$ are in million yuan.

$\mathrm{X}_{t j}$ is a vector of observed product attributes, including a constant term, log of fuel cost, vehicle size, engine size, a dummy for automatic transmission, brand dummies, year fixed effects. In addition, we control for speed of delivery and information exposure using the distance between the destination market and the headquarter province. We use the number of dealers in each province-brand pair to control for market access. Finally, we include province and vehicle segment interactions to control for market-specific preference for different vehicle types. For example, provinces with a larger average household size or hilly terrains are likely to exhibit stronger preference for SUVs.

$\mathrm{X}_{t j k}$ stands for the kth attributes of product $j . \tilde{\beta}_{m t i k}$ is the random taste by household $i$ for attribute $k$ due to unobserved household demographics. We define this taste as

$$
\tilde{\beta}_{m t i k}=\bar{\beta}_{k}+\sigma_{k} v_{m t i k},
$$

which follows a normal distribution with mean $\bar{\beta}_{k}$ and standard deviation $\sigma_{k}$. We allow a random taste for three attributes: the constant term and fuel cost in addition to price, given their importance in affecting consumer demand ${ }^{24}$. The random coefficient for the constant term, $v_{m t i 1}$, captures household $i$ 's preference for the unobserved outside option, such as cars they already own or access to public transportation. Taste dispersion $\sigma$ for all other attributes is assumed to be 0 .

$\xi_{m t j}$ captures all unobserved product attributes, such as advertising or quality of customer service as perceived by buyers in market $m$ and year $t$. The remaining terms in equation (3) are $\mathrm{B}_{j}, \zeta_{m}$, and $\eta_{t}$, which stand for brand, market by vehicle segment, and year fixed effects, respectively ${ }^{25}$.

To facilitate the discussion on identification and estimation below, we rewrite the utility function

\footnotetext{
${ }^{24}$ We have experimented with a random coefficient for engine size, but the estimate is rarely significant.

${ }^{25}$ We include dummies for markets interacted with three vehicle segments: Sedan, SUV, and MPV. There are $31 * 3-$ $1=92$ dummies, and the default group is Beijing Sedan. Small/mini sedans, compact sedans, and medium/large sedans are combined into one Sedan segment, since the classification of these groups is highly correlated with size and engine displacement.
} 
as:

$$
\begin{aligned}
u_{m t i j} & =\delta_{m t j}+\mu_{m t i j}+\varepsilon_{m t i j}, \\
\delta_{m t j} & =\mathrm{X}_{t j} \bar{\beta}+\mathrm{B}_{j}+\zeta_{m}+\eta_{t}+\xi_{m t j} \\
\mu_{m t i j} & =-e^{\bar{\alpha}_{m t i}} * y_{m t i}^{\alpha_{1}} * e^{\sigma_{p} v_{m t i}} * \mathrm{p}_{m t j}+\sum_{k=1}^{K} \mathrm{X}_{t j k} \sigma_{k} v_{m t i k}
\end{aligned}
$$

where $\mu_{m t i j}$, the household-specific utility, depends on household characteristics, but $\delta_{m t j}$, the mean utility, does not.

We use $\theta_{1}$ to denote parameters in the $\delta_{m t j}$, which we call linear parameters, and $\theta_{2}$ to denote parameters in $\mu_{m t i j}$, which we call non-linear parameters, following Berry et al. (1995). The nonlinear parameters include: $\theta_{2}=\left\{\bar{\alpha}_{1}, \bar{\alpha}_{2}, \bar{\alpha}_{3}, \bar{\alpha}_{4}, \rho_{1}, \rho_{2}, \rho_{3} \sigma_{p}, \sigma_{1}, \sigma_{2}\right\}$, where $\bar{\alpha}_{1}, \bar{\alpha}_{2}, \bar{\alpha}_{3}, \bar{\alpha}_{4}$ are price coefficients, $\rho_{1}, \rho_{2}, \rho_{3}$ are local protection discounts, and $\sigma_{p}, \sigma_{1}, \sigma_{2}$ are parameters that affect the dispersion of random coefficients. The probability that household $i$ chooses product $j$ is:

$$
\operatorname{Pr}_{m t i j}\left(\mathrm{p}, \mathrm{X}, \xi, y_{m t i}, \mathrm{D}_{m t i}, \theta_{1}, \theta_{2}\right)=\frac{e^{\delta_{m t j}\left(\theta_{1}\right)+\mu_{m t i j}\left(\theta_{2}\right)}}{1+\sum_{h=1}^{J_{m}}\left[e^{\delta_{m t h}\left(\theta_{1}\right)+\mu_{m t i h}\left(\theta_{2}\right)}\right]}
$$

The individual choice probability can then be aggregated to obtain market shares, which are matched to observed data to estimate model parameters.

\subsection{Supply}

We estimate the demand and supply equations separately. Our supply-side specification follows Berry et al. (1995) with a few minor modifications. First, instead of choosing the optimal price in every market, a firm chooses one national price for each model that it produces to maximize its total profits in a given year. National pricing is likely a reasonable approximation for the Chinese market because retail price maintenance is a common practice ( $\mathrm{Li}$ et al., 2015). Second, taxes levied on automobile purchase is high in China and can account for as much as $50 \%$ of the final transaction

price. This creates a sizeable wedge between the price paid by consumers and the sales revenue accrued to firms. We explicitly model how taxes affect firms' profit function.

The annual national profit for firm $f$ is (we suppress subscript $t$ for simplicity):

$$
\begin{aligned}
\pi_{f} & =\sum_{m=1}^{\mathrm{M}} \sum_{j \in \mathscr{F}}\left(\mathrm{p}_{j}^{0}-\mathrm{T}_{j}\left(\mathrm{p}_{j}^{0}\right)-\mathrm{mc}_{j}\right) \mathrm{M}_{m} \mathrm{~s}_{m j} \\
& =\sum_{j \in \mathscr{F}}\left(\mathrm{p}_{j}^{0}-\mathrm{T}_{j}\left(\mathrm{p}_{j}^{0}\right)-\mathrm{mc}_{j}\right) \mathrm{S}_{j},
\end{aligned}
$$


where $\mathscr{F}$ is the set of all products by firm $f, \mathrm{p}_{j}^{0}$ is the manufacturer suggested retail price MSRP, $\mathrm{T}_{j}$ refers to total tax and is a function of the sales price, $\mathrm{mc}_{j}$ is the marginal cost of product $j . \mathrm{M}_{m}$ is market size, measured by the number of households in market $m . s_{m j}$ is product $j$ 's share in market $m . \mathbf{M}_{m} s_{m j}$ is the number of automobile $j$ sold in market $m$. In the second line, we use $\mathbf{S}_{j}$ to represent product $j$ 's national sales. Here we make two simplifying assumptions on the marginal cost. First, the marginal cost for each model is constant across all markets and does not depend on the distance between where it is produced and where it is sold ${ }^{26}$. Second, the marginal cost is independent of quantity.

Each firm chooses $\left\{\mathrm{p}_{j}^{0}, j \in \mathscr{F}\right\}$ to maximize its total profits. Given this assumption, $\mathrm{p}_{j}^{0}$ satisfies the following first-order condition:

$$
S_{j}\left(1-\frac{\partial \mathrm{T}_{j}}{\partial \mathrm{p}_{j}^{0}}\right)+\sum_{r \in \mathscr{F}}\left(\mathrm{p}_{r}^{0}-\mathrm{T}_{r}-\mathrm{mc}_{r}\right) \frac{\partial \mathrm{S}_{r}}{\partial \mathrm{p}_{j}^{0}}=0, \forall j
$$

Define $\Delta$ as a $J$ by $J$ matrix, whose $(j, r)$ th term is $-\frac{\partial \mathrm{S}_{r}}{\partial \mathrm{p}_{j}^{0}}$ if $r$ and $j$ are produced by the same firm, and 0 otherwise. The first-order conditions can now be written in vector notation as:

$$
\mathrm{S}\left(1-\frac{\partial \mathrm{T}}{\partial \mathrm{p}^{0}}\right)-\Delta\left(\mathrm{p}^{0}-\mathrm{T}-\mathrm{mc}\right)=0
$$

which implies

$$
\mathrm{p}^{0}=\mathrm{mc}+\mathrm{T}+\Delta^{-1}\left[\mathrm{~S}\left(1-\frac{\partial \mathrm{T}}{\partial \mathrm{p}^{0}}\right)\right] .
$$

In order to back out marginal costs from the equation above, we need to calculate $\mathrm{T}, \frac{\partial \mathrm{T}}{\partial \mathrm{p}^{0}}$ and $\Delta$.

In China, sales of new vehicle is subjected to four types of taxes: consumption tax $\left(t_{j}^{c}\right)$, valueadded tax $\left(t_{j}^{v a}\right)$, sales tax $\left(t_{j}^{s}\right)$, and import tariffs $\left(t_{j}^{i m}\right)$. We use these letters to denote the tax rates. An unconventional feature of the tax system in China is that the "pre-tax" price includes the consumption tax, which depends on the engine size of the vehicle. For example, if the pre-tax price of a vehicle is $100 \mathrm{k}$ yuan and the consumption tax is $25 \%$, the manufacturer gets $75 \mathrm{k}$ yuan from each unit of the vehicle sold, while the government collects the remaining $25 \mathrm{k}$ yuan as the consumption tax. The other three types of taxes are charged as a percentage of the pre-tax price. Valued-added tax is $17 \%$ for all models, import tariff is $25 \%$ for imported products, while sales tax is normally set at $10 \%$ but was lowered to $5 \%$ and $7.5 \%$ for vehicles with engine displacement no more than 1.6 liters in 2009 and 2010, respectively. Let $\mathrm{p}_{j}^{0}$ denote the retail price paid by consumers, and $\mathrm{p}_{j}^{f}$

\footnotetext{
${ }^{26}$ Allowing the marginal cost to depend on distance between the production county and the destination market does not affect the key coefficients that capture cost advantages of private firms.
} 
denote firm's per-unit revenue. We have:

$$
\begin{aligned}
\mathrm{p}_{j}^{0} & =\frac{\mathrm{p}_{j}^{f}}{1-t_{j}^{c}} *\left(1+t_{j}^{v a}+t_{j}^{s}+t_{j}^{i m}\right), \\
\mathrm{T}_{j} & =\mathrm{p}_{j}^{0}-\mathrm{p}_{j}^{f}=\mathrm{p}_{j}^{0}-\frac{\mathrm{p}_{j}^{0} *\left(1-t_{j}^{c}\right)}{1+t_{j}^{v a}+t_{j}^{s}+t_{j}^{i m}}, \text { and } \\
\frac{\partial \mathrm{T}_{j}}{\partial \mathrm{p}_{j}^{0}} & =1-\frac{1-t_{j}^{c}}{1+t_{j}^{v a}+t_{j}^{s}+t_{j}^{i m}}
\end{aligned}
$$

We obtain the tax rates for all vehicle models, calculate $\mathrm{T}$ and $\frac{\partial \mathrm{T}}{\partial \mathrm{p}^{0}}$ using equation (8) and (9), derive $\Delta$ from demand estimates, and back out marginal cost for each model and year $m c_{t j}$. Marginal cost is assumed to be log-linear in attributes:

$$
\ln (\mathrm{mc})_{t j}=W_{t j} \phi+\omega_{t j}
$$

where $W_{t j}$ includes logs of vehicle attributes, firm-type dummies, and year dummies, and $\omega_{t j}$ stands for unobserved cost shock to model $j$ in year $t$. We are most interested in the coefficients of firmtype dummies, which capture relative cost efficiency between different types of firms.

\subsection{Identification and Estimation}

Our discussion of identification focuses on two sets of key parameters: a) the price discounts $\rho_{1}, \rho_{2}$, and $\rho_{3}$ that capture the extent of local protectionism, and $b$ ) the coefficients that measure consumer price sensitivity. We then briefly describe how all parameters are estimated.

To address both the price endogeneity arising from the correlation between prices and unobserved product attributes $\xi_{m t j}$ and the fact that market shares need to be "instrumented" in these nonlinear models (Berry and Haile, 2014; Gandhi and Houde, 2016), we use three sets of instruments. The first set of instruments, or the BLP instruments, includes the number of products in the same vehicle segment by the same firm and the number of products in the same vehicle segment by rival firms. They capture the intensity of competition and affect firms' pricing decisions. Non-price attributes serve as instruments for themselves and are assumed to be orthogenal to the unobserved attributes. We further add home market dummies by ownership type to the list of instruments, so that contemporaneous variations in product quality $\xi_{m t j}$ is orthogonal to the home-market status.

The second set of instruments include the four tax rates. The non-linear feature of the Chinese tax system creates model-specific tax rates that depend on engine size, engine displacement, and the 
import status ${ }^{27}$. The rationale for these tax policies is to promote sales of small and fuel-efficient vehicles to reduce pollution and congestion. The range of the consumption tax is especially large, from $1 \%$ for engine size equal to or smaller than $1.0 \mathrm{~L}$ to $40 \%$ for engine size above $4.0 \mathrm{~L}$. These tax schemes introduce jumps in prices and are strong instruments.

The third set of instruments exploit panel variation in demographics, especially income. As illustrated in Table 4, there is a noticeable change in Chinese households' income distribution in our sample period and the fraction of households with annual income less than 48k yuan dropped from $69 \%$ in 2009 to $55 \%$ in 2011 . Regional inequality is also pronounced. In 2009, the median household income in the richest province is 54,000 yuan, which is around three times of that in the median province and over five times of that in the poorest province. We first construct differences in vehicle attributes following Gandhi and Houde (2016) and then interact these attribute differences with different quantiles of the income distribution in each market.

Consumer price sensitivity is captured by $e^{\bar{\alpha}_{m t i}} * y_{m t i}^{\alpha_{1}} * e^{\sigma_{p} v_{m t i}}$ as shown in equation (5), with six key parameters: $\left\{e^{\bar{\alpha}_{1}}, e^{\bar{\alpha}_{2}}, e^{\bar{\alpha}_{3}}, e^{\bar{\alpha}_{4}}, \alpha_{1}, \sigma_{p}\right\}$. Several data patterns help to identify these coefficients. First, more expensive models have higher market shares in provinces with higher household income. The second and more powerful source of identification is the micro-moments: households with higher income are more likely to buy new vehicles, and much more likely to buy expensive vehicles such as large sedans and SUVs than low-income households. These moments help to identify $\left\{\bar{\alpha}_{1}, \bar{\alpha}_{2}, \bar{\alpha}_{3}, \bar{\alpha}_{4}\right\}$. A high $\bar{\alpha}_{i}$ makes all consumers in income group $i$ dislike price more and less likely to buy new vehicles. If the model over-predicts the fraction of buys from income group $i$, $\bar{\alpha}_{i}$ will increase until the model's prediction aligns with the level observed in our micro-moments. Finally, the substitution patterns across markets and overtime helps to identify the dispersion parameter, $\sigma_{p}$. Local subsidies $\rho_{1}, \rho_{2}$, and $\rho_{3}$ are identified from differences in home market shares relative to the national shares.

Demand-side parameters are estimated by simulated GMM with two sets of moment conditions. The first set of moment conditions (macro moments) is constructed using excluded instruments, exogenous vehicle attributes, and their interactions. The second set of moment conditions (micro moments) are based on the Ford survey of new vehicle buyers. These moment conditions require the model-predicted fractions of buyers in each income bracket to match the observed shares for each of the three years in the survey, both across all vehicle segments and separately for each of the four vehicle segments. There are nearly 200 macro-moments and 45 micro-moments. ${ }^{28}$

\footnotetext{
${ }^{27}$ As discussed in section 5.2, the total tax rate as a fraction of the retail price is $\frac{1-t_{j}^{c}}{1+t_{j}^{v a}+t_{j}^{s}+t_{j}^{i m}}$.

${ }^{28}$ For micro-moments, we have three years, four income brackets, five segments as well as all segments combined, which leads to $3 * 5 * 3=45$ micro-moments. Note that we do not include moments associated with the fifth vehicle segment (MPV) because the fraction of buyers in each income group for MPV is linearly dependent from those for the other segments and across all vehicle segments. There are seven excluded IVs, which are the number of own and rival products in the same segment, consumption tax rate and the total tax rate, dummy for local private, SOE, and
} 
Our macro-moments have 19,505 observations, which are the total number of vehicle models sold in each province and year. The number of observations for the micro moments is the number of survey respondents, which increases from $20.5 \mathrm{k}$ in 2009 to $34 \mathrm{k}$ to 2011 . We use optimal weighting matrix and scale each set of moments by the appropriate number of observations.

The estimation is carried out in simulated optimal GMM with a nested contraction mapping as is now standard in the BLP literature. It involves two steps. In step one, we use weighting matrix $\left(\begin{array}{cc}\left(Z^{\prime} Z\right)^{-1} & 0 \\ 0 & \Omega\end{array}\right)$, where $Z$ is the set of macro instruments and $\Omega$ is the variance of the micro moments, to obtain consistent estimates of the parameters and the optimal weighting matrix. In step two, we re-estimate the model with the optimal weighting matrix to obtain the final parameter estimates.

As pointed out by Dube et al. (2012), Knittel and Metaxoglou (2014) and a few others, computational issues are important in nonlinear estimations like BLP. We provide the analytic gradient for both the macro- and micro- moments, set the convergence criterion for the contraction mapping to $1 e^{-14}$, and use a large number of Halton simulation draws (between 500 and 1000 draws) to improve the accuracy of numeric integration. For each estimation run, we use 20 to 50 starting values and only keep parameter estimates that produce the lowest GMM objective function value and satisfy the first order condition (the maximum absolute value of the gradient vector to the objective function value is smaller than $1 e^{-7}$ ).

\section{Estimation Results}

\subsection{Demand}

Table 8 shows estimation results from three specifications of the random coefficient model. In all three specifications, the linear parameters are those in the mean utility defined in equation (4); the price coefficients and random coefficients are in the household-specific utility defined in equation (5). Column (1) uses only macro moments, while columns (2) and (3) use both macro and micro moment conditions. Column (2) does not control for the number of dealers by market and brand.

In the first specification (column 1 of Table 8), we identify the price coefficients and the random coefficients from substitution patterns and the correlation between demand and income levels in each market only. As illustrated in Table 9, the model fails to predict the income distribution among car buyers reported in the Ford survey. When we introduce the micro-moments in specifications (2) and (3), the model predicts more elastic demand by poor households and produces a much

JV. Our macro-moments include these excluded IVs and their interactions, seven product attributes, 92 province by vehicle type dummies, two year fixed effects, one dummy for Beijing 2011 lottery policy that reduces car demand, and 73 brand dummies. 
better fit of the observed income distribution. The largest prediction error is $2.3 \%$, and the average prediction error is only $1.2 \%$. The fit for the segment-specific income shares is also decent. Results from specifications (2) and (3) are similar except that controlling for the number of dealers slightly reduces the estimated discount rates for local JV and SOE products. As in the RD analysis, discount rate for local private products is insignificant across the columns. In the discussion that follows, we use coefficient estimates from the third column (our preferred specification).

Table 8: Results from the RC model

\begin{tabular}{|c|c|c|c|c|c|c|}
\hline & \multicolumn{2}{|l|}{ (1) } & \multicolumn{2}{|l|}{ (2) } & \multicolumn{2}{|c|}{ (3) } \\
\hline & Est. & S.E. & Est. & S.E & Est. & S.E \\
\hline \multicolumn{7}{|l|}{ Linear parameters } \\
\hline $\log ($ Fuel cost $)$ & $-4.53 * * *$ & 0.23 & $-1.66 * * *$ & 0.24 & $-1.66 * * *$ & 0.24 \\
\hline $\log ($ Displacement $)$ & $1.85 * * *$ & 0.17 & $3.65 * * *$ & 0.18 & $3.58 * * *$ & 0.18 \\
\hline $\log ($ Size $)$ & $5.21 * * *$ & 0.24 & $7.53 * * *$ & 0.25 & $7.47 * * *$ & 0.25 \\
\hline Auto Transmission & $0.39 * * *$ & 0.03 & $0.71 * * *$ & 0.03 & $0.70 * * *$ & 0.03 \\
\hline Distance to headquarter & $-0.05 * * *$ & 0.02 & $-0.06 * * *$ & 0.02 & $-0.06 * * *$ & 0.02 \\
\hline Number of dealers & $0.01 * * *$ & 0.00 & & & $0.01 * * *$ & 0.00 \\
\hline \multicolumn{7}{|l|}{ Price coefficients } \\
\hline$e^{\bar{\alpha}_{1}}$ & $10.23 * * *$ & 1.00 & $41.06^{* * *}$ & 0.41 & $41.33^{* * *}$ & 0.42 \\
\hline$e^{\bar{\alpha}_{2}}$ & $1.46^{* * *}$ & 0.05 & $23.25 * * *$ & 0.26 & $23.24 * * *$ & 0.26 \\
\hline$e^{\bar{\alpha}_{3}}$ & $0.68 * * *$ & 6.54 & $7.83 * * *$ & 0.14 & $7.75 * * *$ & 0.14 \\
\hline$e^{\bar{\alpha}_{4}}$ & 0.50 & 0.32 & $6.48 * * *$ & 0.15 & $6.39 * * *$ & 0.15 \\
\hline Private discount, $\rho_{1}$ & 0.04 & 0.07 & 0.03 & 0.04 & 0.05 & 0.04 \\
\hline $\mathrm{JV}$ discount, $\rho_{2}$ & $0.22 * * *$ & 0.04 & $0.19 * * *$ & 0.02 & $0.17 * * *$ & 0.02 \\
\hline SOE discount, $\rho_{3}$ & $0.36 * * *$ & 0.05 & $0.29 * * *$ & 0.03 & $0.28 * * *$ & 0.03 \\
\hline \multicolumn{7}{|l|}{ Random coefficients } \\
\hline Constant, $\sigma_{1}$ & -4.29 & 2.63 & $-3.93 * * *$ & 0.23 & $-3.89 * * *$ & 0.23 \\
\hline $\log ($ Fuel cost $), \sigma_{2}$ & $-3.16 * * *$ & 0.73 & $-1.15 * * *$ & 0.06 & $1.14 * * *$ & 0.06 \\
\hline price, $\sigma_{p}$ & $-0.24 * * *$ & 0.10 & $1.36^{* * *}$ & 0.04 & $1.37 * * *$ & 0.04 \\
\hline
\end{tabular}

Note: The number of observations: is 19,505 . * $\mathrm{p}<0.1$, ** $\mathrm{p}<0.05, * * * \mathrm{p}<0.01$

All linear parameter estimates are intuitively signed and statistically significant. All else equal, consumers dislike vehicles with higher fuel costs, and prefer larger and more powerful vehicles as well as vehicles with automatic transmission. A $10 \%$ increase in fuel cost reduces sales by around $14.6 \%$, while a $10 \%$ increase in displacement and vehicle size increases sales by around $40.7 \%$ and $103.8 \%$, respectively. Conversion from manual to automatic transmission increases sales by around $101.3 \%$. Distance to headquarter and the number of dealers control for information and the ease of access. Each additional dealer store in a province increases sales by around $1 \%$ (the average number of dealers is 21 ). Sales decrease by about $5.8 \%$ for every $1000 \mathrm{~km}$ further away from a model's headquarter province.

The estimates of $\bar{\alpha}$ s decrease monotonically with the income brackets, consistent with our prior that higher income consumers are less price sensitive. Consider a car priced at 140k yuan, 
Table 9: Model Fit in Micro-moments

\begin{tabular}{llcccc}
\hline \hline year & Income group & observed share & $\begin{array}{c}\text { Predicted share } \\
\text { Specification (1) }\end{array}$ & $\begin{array}{c}\text { Predicted share } \\
\text { Specification (2) }\end{array}$ & $\begin{array}{c}\text { Predicted share } \\
\text { specification(3) }\end{array}$ \\
\hline 2009 & $<48 \mathrm{k}$ & $15.8 \%$ & $7.7 \%$ & $16.1 \%$ & $16.1 \%$ \\
& $48 \mathrm{k}-96 \mathrm{k}$ & $33.6 \%$ & $64.0 \%$ & $32.0 \%$ & $32.0 \%$ \\
& $96 \mathrm{k}-144 \mathrm{k}$ & $32.0 \%$ & $18.1 \%$ & $30.3 \%$ & $30.3 \%$ \\
2010 & $<48 \mathrm{k}$ & $10.9 \%$ & $4.7 \%$ & $11.0 \%$ & $11.0 \%$ \\
& $48 \mathrm{k}-96 \mathrm{k}$ & $26.9 \%$ & $64.5 \%$ & $29.2 \%$ & $29.2 \%$ \\
& $96 \mathrm{k}-144 \mathrm{k}$ & $33.3 \%$ & $19.9 \%$ & $31.3 \%$ & $31.3 \%$ \\
2011 & $<48 \mathrm{k}$ & $9.3 \%$ & $5.7 \%$ & $10.3 \%$ & $10.3 \%$ \\
& $48 \mathrm{k}-96 \mathrm{k}$ & $26.2 \%$ & $61.5 \%$ & $27.5 \%$ & $27.5 \%$ \\
& $96 \mathrm{k}-144 \mathrm{k}$ & $33.7 \%$ & $19.1 \%$ & $34.6 \%$ & $34.6 \%$ \\
\hline \hline
\end{tabular}

Notes: We drop the highest income bracket from each year. The parameter estimates for specifications (1), (2) and (3) are presented in Table 8.

the median price in our sample in 2011. Average price elasticities are -91.0, -36.4, -8.6 and -2.9 when a household's income is $24 k$ yuan, $72 k$ yuan, $120 k$ yuan, and $288 k$ yuan, respectively. ${ }^{29}$ Since most low-income households have little accumulated wealth and limited access to bank loans, they rarely purchase new vehicles.

On the other hand, at a given income level, there is large dispersion in the disutility of price, as suggested by our estimate $\hat{\sigma}_{\mathrm{p}}=1.37$. Consider two consumers with the same income $\left(y_{m t 1}=y_{m t 2}=\right.$ 0.12 mill Yuan) but different draws of the random price sensitivity $\left(v_{m t 1}^{p}=1\right.$, and $\left.v_{m t 2}^{p}=-1\right)$. Our model predicts that for a car priced at 140k yuan, demand elasticity is -29.9 and -2.3 for those two households, respectively. This random coefficient captures unobserved wealth and other factors that relate to the propensity of buying cars. It helps explain the sales of expensive models in provinces that have few high-income households.

To help understand the magnitude of the parameter estimates, we plot own-price elasticities and Lerner index $\frac{P-m c}{P}$ against vehicle prices for 234 models in 2011 in Figure 6. Own price elasticities range from -2.40 to -4.96 , with a median of -3.74 . The median price elasticity for private, SOE, JV, and imported products is $-4.28,-4.18,-3.60$ and -2.91 , respectively. More expensive models tend to have less elastic demand as shown in the top panel of Figure $6 .{ }^{30}$ The magnitudes of the own price elasticities are similar to those obtained from the U.S automobile market in Berry et al. (1995) and Petrin (2002). Although average household income is much lower in China than in the US, our micro-moments suggest that most prospective car buyers in China come from a relatively affluent class. The bottom panel of Figure 6 shows the Lerner index using after-tax profits and revenues.

\footnotetext{
${ }^{29}$ Income is in millions of yuan in our estimation, or $y_{m t i}=0.024,0.072,0.12,0.288$ for this example.

${ }^{30}$ Fixing households' income and preference, more expensive models have more elastic demand in models like ours. On the other hand, expensive models target consumers who are wealthier and less sensitive to prices. The second effect in general dominates. However, the income distribution we use is bounded above and capped at the maximum income observed in our 2005 Census. For the ultra-expensive models that are priced above 500,000 RMB $(\$ 75,000)$, the upper bound of income binds and the elasticity starts to increase after a certain point.
} 
The profit margin varies from $21.0 \%$ to $42.8 \%$, with a median of $27.7 \%$. More expensive models have a larger Lerner index as their consumer base is less sensitive to prices.

Figure 6: Price Elasticities and Markup-Price Ratios
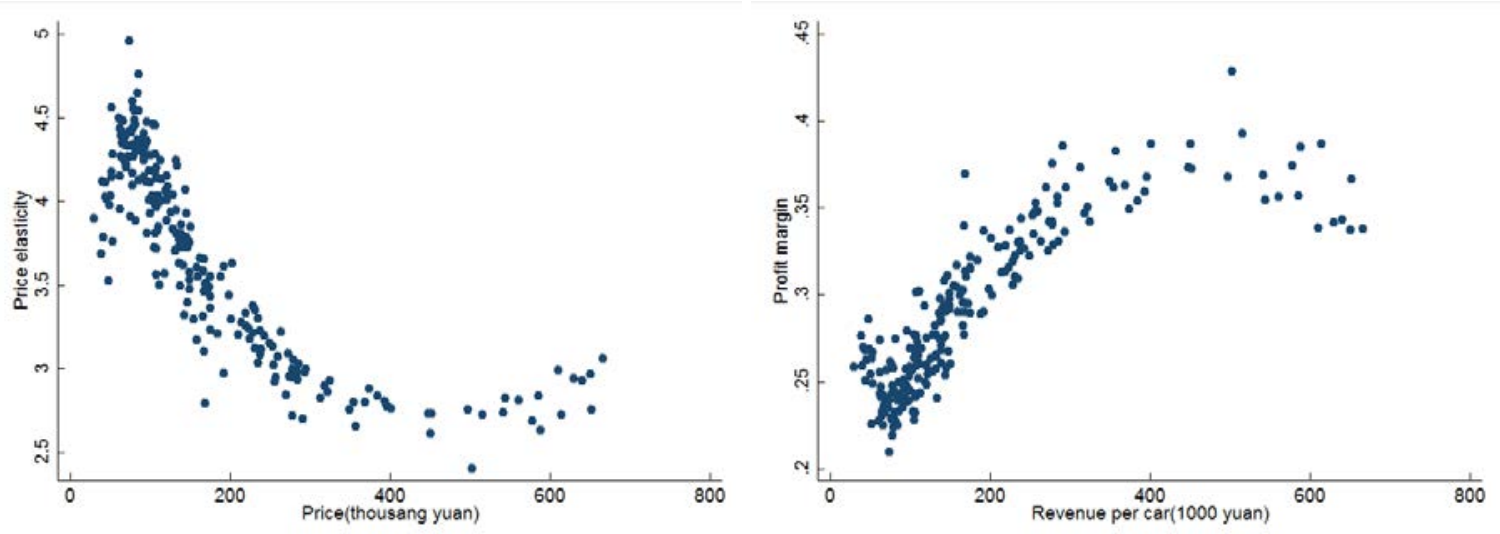

Local protection is equivalent to a $17 \%$ discount in retail price for local $\mathrm{JV}$ products, and a $28 \%$ discount for local SOE products. There are several reasons to believe that these estimates are reasonable. First, these estimates are in line with Table 1, where reported direct subsidies for local non-electric vehicles are as high as $15 \%$ of the retail price. Second, besides direct rebates, subsidies come in other forms including waivers of registration fees and tolls and low-interest loans. There also exist implicit barriers to market access for non-local products. Our estimates encapsulate all forms of local protectionism. Third, these discounts, together with the variations in own-price elasticites across different products, are consistent with the magnitude of home bias for JV and SOE products reported in RD regressions in Table 6. For example, a 17\% price discount for JVs and a price elasticity of -3.6 would imply roughly a $60 \%$ increase in sales, compared to $52 \%$ estimated in Table 6. Lastly, as anecdotal evidence, our estimates imply a total subsidy of 4.3 million yuan in Chongqing in 2011, which is comparable to the reported subsidy of 3 million in Chongqing in 2012 (Table 1).

\subsection{Supply}

With demand-side parameters estimated, we use the optimal pricing equation (7) to back out marginal costs. To examine how car attributes and ownership types affect marginal costs, we regress log of marginal costs on these controls using equation (10) and report the results in Table 10. There are 631 observations in total, one for each model-year, since prices are set at the national level. Column (1) includes the key attributes and their squared terms, and separate dummies for automatic transmission, SUV and MPV. Column (2) adds brand fixed effect estimates from section 
6.1 and their quadratic terms. ${ }^{31}$ Column (3) further includes estimated $\xi_{m t j}$ from the demand-side to control for unobserved product quality. We average $\xi_{m t j}$ across provinces to obtain the national average. In Column (4), we break down JV products by the origin of the foreign partner.

The coefficients on car attributes are in general intuitive. Marginal costs are higher for larger engine size, larger cars, cars with auto transmission, and SUVs. Multi-purpose vehicle segment includes a variety of specialized cars, including mini-buses that are often of lower quality and cheaper. Their marginal cost is lower than that for the other two segments. The only puzzling coefficient is that of fuel costs, which implies that it is cheaper to produce more fuel efficient cars. This might be driven by the high correlation between fuel costs, engine size, and car size.

We use SOEs as the reference group when we examine relative cost efficiency among four different ownership types. In Column (1), the marginal cost of private firms is $11 \%$ lower than that of SOEs, while JVs and foreign firms have cost disadvantages as high as $22 \%$ and $34 \%$. Such results are mostly driven by different product mix between private/SOE and JV/foreign firms. Compared with domestic firms, JVs and foreign firms produce more high-end products (leather seats, sunroof, etc.) that are more likely to use high-quality inputs. Once we control for brand fixed effect estimates (Column (2) onward), the gaps in marginal costs shrink by a large margin. Private firms are still the most cost efficient among the four groups, and their marginal cost is about $6 \%$ lower than that of the SOEs. Imports have a $10 \%$ cost disadvantage that could be driven by high transportation costs.

Surprisingly, JVs do not seem to be more cost efficient than SOEs, even though all foreign partners are well-known leading auto producers in the world. When we separate JVs by the country origin of their foreign partners, we find that JVs with US and Japanese partners appear to be slightly more cost efficient than JVs with European or Korean partners, but the differences are statistically insignificant. The fact that JVs do not appear more efficient than SOEs might be related to how they are managed. The domestic partner of every JV in our sample is an SOE. ${ }^{32}$ These domestic partners hold at least a 50\% stake in the JVs and in most cases control the operation and management of the firm, while the foreign partner mainly provides the technology.

The medium marginal cost of a private brand in our sample is around 44,000 yuan. The transfer of vehicle production from private firms to JVs or SOEs would lead to a cost increase of about $6 \%$, or around 3,000 yuan per vehicle.

\footnotetext{
${ }^{31}$ We can not use brand fixed effects directly since they absorb all of the ownership coefficients.

${ }^{32}$ The only private firm that formed a joint venture with foreign producers in our sample is Youngman Lotus, but it had negligible sales and ceased passenger car production in 2015 and was dropped in our estimation. The first partnership between a prominent private and a foreign auto producer happened in 2010, when BYD and Mercedes-Benz formed a joint venture BYD Daimler. Their first production debuted in 2014.
} 
Table 10: Results from cost-side estimations

\begin{tabular}{|c|c|c|c|c|c|c|c|c|}
\hline & \multicolumn{2}{|l|}{ (1) } & \multicolumn{2}{|c|}{ (2) } & \multicolumn{2}{|c|}{ (3) } & \multicolumn{2}{|c|}{ (4) } \\
\hline & Est. & S.E. & Est. & S.E & Est. & S.E & Est. & S.E \\
\hline \multicolumn{9}{|l|}{ Ownership types } \\
\hline Private & $-0.11 * * *$ & 0.03 & $-0.06 * * *$ & 0.02 & $-0.06 * * *$ & 0.02 & $-0.06 * * *$ & 0.02 \\
\hline $\mathrm{JV}$ & $0.22 * * *$ & 0.02 & -0.00 & 0.02 & 0.00 & 0.02 & & \\
\hline $\mathrm{JV}$ (Europe) & & & & & & & 0.02 & 0.03 \\
\hline JV(Japan) & & & & & & & -0.03 & 0.03 \\
\hline JV(Korea) & & & & & & & 0.01 & 0.04 \\
\hline JV(US) & & & & & & & -0.02 & 0.02 \\
\hline Imports & $0.34 * * *$ & 0.04 & $0.10 * * *$ & 0.03 & $0.09 * * *$ & 0.03 & $0.10 * * *$ & 0.03 \\
\hline \multicolumn{9}{|l|}{ Attributes } \\
\hline Fuel use & 0.13 & 0.09 & $0.19 * * *$ & 0.06 & $0.18 * * *$ & 0.06 & $0.18 * * *$ & 0.06 \\
\hline Fuel use $^{2}$ & $-0.01 *$ & 0.01 & $-0.01 * *$ & 0.00 & $-0.01 * *$ & 0.00 & $-0.01 * *$ & 0.00 \\
\hline Engine size & $1.22 * * *$ & 0.18 & $0.74 * * *$ & 0.12 & $0.73 * * *$ & 0.12 & $0.74 * * *$ & 0.12 \\
\hline Engine size ${ }^{2}$ & $-0.14 * * *$ & 0.04 & $-0.08 * * *$ & 0.03 & $-0.08 * * *$ & 0.02 & $-0.08 * * *$ & 0.02 \\
\hline Size & $-0.32 * * *$ & 0.11 & 0.05 & 0.08 & 0.10 & 0.07 & 0.09 & 0.08 \\
\hline Size $^{2}$ & $0.03 * * *$ & 0.01 & 0.01 & 0.01 & 0.00 & 0.01 & 0.00 & 0.01 \\
\hline Auto Trans. & $0.18 * * *$ & 0.02 & $0.12 * * *$ & 0.01 & $0.12 * * *$ & 0.01 & $0.12 * * *$ & 0.01 \\
\hline SUV & 0.03 & 0.03 & $0.08 * * *$ & 0.02 & $0.07 * * *$ & 0.02 & $0.08 * * *$ & 0.02 \\
\hline MPV & $-0.08 * * *$ & 0.04 & $-0.08 * * *$ & 0.03 & $-0.08 * * *$ & 0.02 & $-0.07 * * *$ & 0.02 \\
\hline \multicolumn{9}{|l|}{ Fixed effects } \\
\hline year FE & $\mathrm{Y}$ & & $\mathrm{Y}$ & & $\mathrm{Y}$ & & $\mathrm{Y}$ & \\
\hline Brand FE Estimates & $\mathrm{N}$ & & $\mathrm{Y}$ & & $\mathrm{Y}$ & & $\mathrm{Y}$ & \\
\hline $\bar{\xi}$ & $\mathrm{N}$ & & $\mathrm{N}$ & & $\mathrm{Y}$ & & $\mathrm{Y}$ & \\
\hline
\end{tabular}

Note: The number of observations is 631. The reference ownership type is SOE. We obtain brand fixed effect estimates and $\bar{\xi}$ from the demand estimation. ${ }^{*} \mathrm{p}<0.1, * * \mathrm{p}<0.05, * * * \mathrm{p}<0.01$.

\section{Simulations and Welfare Analysis}

To quantify the impact of local protection on market outcomes and social welfare, we reset discount rates for local JV and SOE products to 0 and simulate market outcomes where trade barriers across regions are eliminated. We repeat the analysis twice, first without any price change and second allowing auto firms to adjust prices in response to the removal of local protection. We then compare market outcomes and social welfare between the observed and simulated scenarios.

\subsection{Impacts on Market Outcomes}

To evaluate the impact of local protection on prices, we solve for new equilibrium prices without local protection using equation (7) and plot the distributions of percentage price changes induced by local protection in Figure 7. Note that with multi-product firms that experience demand shocks in one market but cannot price discriminate across different markets, patterns of price adjustments in our settings are more complex than that of a single-product firm in a single market. 
Local subsidy enhances protected firms' market power locally. Not surprisingly, $62 \%$ of JV products and $60 \%$ of SOE products experience price increases as a result of greater market power in their home markets. The sign and the magnitude of the price adjustments are highly correlated with the importance of the home market. For example, the largest price hike among SOE products (3.82\%) is by Xiali Vela in 2009, whose home-market sales account for around $72.8 \%$ of its total sales. Firms based in large and wealthy provinces tend to increase prices, while firms with small home markets tend to reduce prices to cope with stiffer competition in their non-local markets.

Price adjustments for private and imported products are smaller in absolute value. On one hand, competition from protected SOE and JV products exerts downward pressure on prices. On the other hand, prices are strategic substitutes. When SOEs and JVs increase their prices, this exerts upward pressure on prices of private and imported cars. The two effects offset each other and net price adjustments are small.

Figure 7: Percentage price changes by firm type

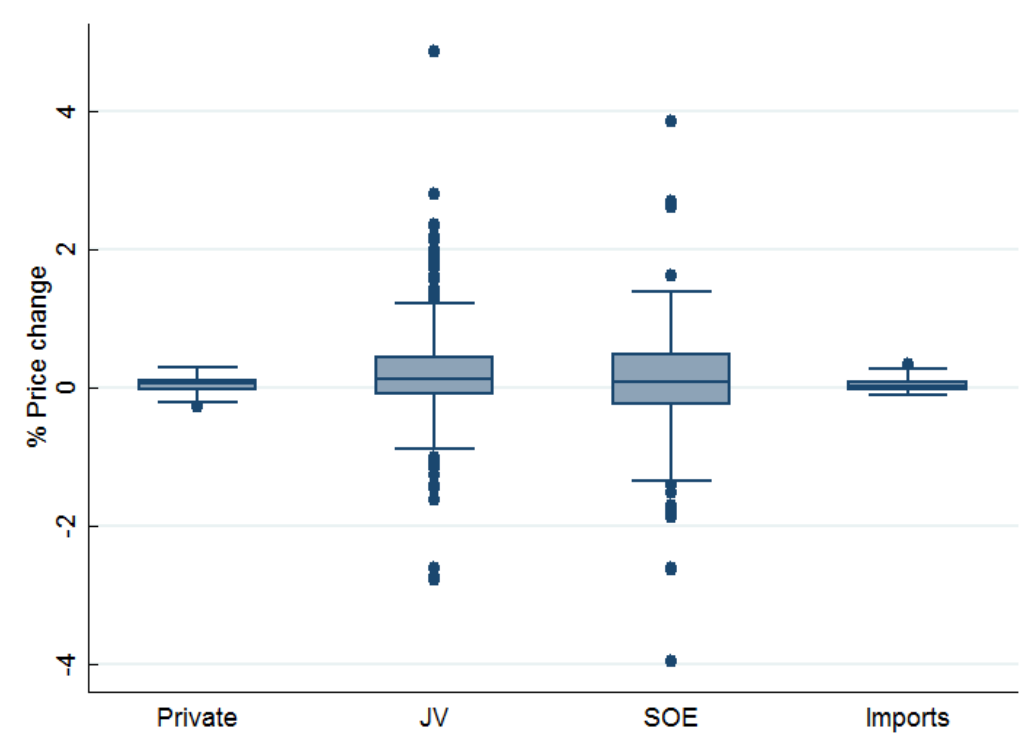

Turning to quantity responses, the top panel of Table 11 shows that local protection increases market shares of JVs and SOEs in their headquarter province by as much as $61.0 \%$ and $244.5 \%$ when prices are fixed at the observed level. In contrast, local protection has a much more modest impact on national vehicle sales, which increase by $3.7 \%$ for SOEs and $1.2 \%$ for JVs. This happens for two reasons. First, there are 31 provinces in China and each firm has only one home market. As a result, home-market sales on average account for $5 \%$ of a firm's national sales. Second, when all provinces protects their local products, a SOE or JV benefits in its home province but faces stiffer competition elsewhere. This kind of business-stealing in other provinces counteracts gains locally. In theory, higher local demand could be entirely offset by lower sales elsewhere, as in 
the classic example of prisoners' dilemma. In our setting, the local benefits on average outweigh losses in other provinces, though there is considerable heterogeneity among different firms and markets. The modest impact on national sales also explains why price adjustments induced by local protection are small.

Total sales by private and foreign firms fall by $2.6 \%$ and $1.1 \%$, respectively, as their prospective consumers switch to the protected local JV or SOE products. Local protection hurts the private firms more than foreign firms for two reasons. First, as shown in the product mix in Table 3 , products by private firms are closer substitutes to SOE products as well as most JV products. Second, imported cars are typically bought by wealthy consumers who care much less about monetary discounts.

Table 11: Impacts of local protection on sales

\begin{tabular}{lccccrr}
\hline \hline Firm type & \multicolumn{3}{c}{ Home-market Sales ('000) } & \multicolumn{3}{c}{ National Sales ('000) } \\
& Before & After & \% Change & Before & After & \% Change \\
\hline \multicolumn{7}{l}{ Without price updates } \\
Private & 217 & 208 & & & & \\
JV & 756 & 1217 & $61.0 \%$ & 16675 & 16877 & $1.2 \%$ \\
SOE & 94 & 324 & $244.5 \%$ & 3964 & 4111 & $3.7 \%$ \\
Imports & & & & 774 & 766 & $-1.1 \%$ \\
& & & & & & \\
With price updates & & & & & \\
Private & 217 & 208 & $-4.2 \%$ & 2857 & 2794 & $-2.2 \%$ \\
JV & 761 & 1217 & $59.9 \%$ & 16715 & 16877 & $1.0 \%$ \\
SOE & 96 & 324 & $236.4 \%$ & 3983 & 4111 & $3.2 \%$ \\
Imports & & & & 773 & 766 & $-0.9 \%$ \\
\hline \hline
\end{tabular}

Price adjustments - higher prices by SOEs and JVs in response to local protection - offset a small part of sales gains by JVs and SOEs from local protection. As shown in the bottom panel of Table 11, when we allow for price changes, local protection increases national sales of SOEs and JVs by $3.2 \%$ and $1.0 \%$ and reduces those of private firms and foreign firms by $2.2 \%$ and $0.9 \%$.

Substitution patterns induced by local protection are summarized in Table 12. The top panel of Table 12 shows that in the absence of price adjustment, $62 \%$ of sales gains by local JV and SOE products come from similar non-local products, while 38\% come from the outside option. $79 \%$ of switchers who would otherwise choose JV substitute to a local JV product, while only $57 \%$ of switchers who would otherwise not buy new cars do so. Such patterns show that households indeed tend to substitute between similar choices: consumers who switch from the outside option usually have low income and are more likely to choose cheaper local SOE products. For the same reason, the number of households that switch from imports (which are mostly high-end luxury brands) to local SOEs is negligible. 
Altogether, local protection leads to 703,000 suboptimal vehicle choices between 2009 and 2011 when prices are held fixed. Allowing price changes increases the total number of distortions to 986,000 , or $4 \%$ of total vehicle sales over our sample period.

Table 12: Substitution patterns induced by local protection

\begin{tabular}{|c|c|c|c|c|c|}
\hline \multirow[b]{2}{*}{ Old choice } & \multicolumn{5}{|c|}{ Substitute to ('000) } \\
\hline & Private & JV & SOE & Imports & Do not buy \\
\hline \multicolumn{6}{|c|}{ Without price updates } \\
\hline Private & & 43 & 32 & & \\
\hline $\mathrm{JV}$ & & 214 & 57 & & \\
\hline SOE & & 57 & 27 & & \\
\hline Import & & 8.2 & 0.4 & & \\
\hline Do not buy & & 150 & 114 & & \\
\hline \multicolumn{6}{|c|}{ With price updates } \\
\hline Private & 0.7 & 51 & 36 & 0.0 & 2.5 \\
\hline $\mathrm{JV}$ & 13 & 302 & 83 & 3.9 & 41 \\
\hline SOE & 11 & 80 & 41 & 0.2 & 25 \\
\hline Import & 0.0 & 9.0 & 0.6 & 0.0 & 0.2 \\
\hline Do not buy & 1.4 & 165 & 121 & 0.0 & \\
\hline
\end{tabular}

\subsection{Welfare Analysis}

We first evaluate the welfare consequences of local protectionism on consumer surplus. To do so, we make two important assumptions: a) revenue neutrality of government subsidies, and b) all subsidies are financed via a lump-sum tax. Assumption b) delivers a conservative estimate of welfare losses since lump-sum taxes create the least distortion. Local protection reduces consumer welfare through two channels. First, it leads to a modest increase in the average vehicle price, as shown in Figure 7. Second, and more importantly, local protection distorts consumer choices toward suboptimal SOE or JV products.

To illustrate the welfare loss of choice distortions, consider a simple example where consumer $i$ in market $m$ obtains a consumer surplus of 10,000 yuan from her top choice product $\mathrm{A}$, and a surplus of 6,000 yuan from a local product B. Suppose the government in market $m$ provides a subsidy of 5,000 yuan to each consumer who purchases B. The subsidy induces consumer $i$ to choose B over A. This substitution entails a welfare loss of 4,000 yuan: the government spends 5,000 yuan subsiding consumer $i$ 's vehicle purchase, but only increases her surplus by 1,000 yuan. We incur such losses whenever local protection causes a consumer to choose a suboptimal local brand that is different from her intrinsic top choice. Importantly, the magnitude of the consumer 
welfare loss is solely determined by the gap in the intrinsic utility between a consumer's top choice and the subsidized product, and is independent of the size of subsidy. ${ }^{33}$

One might be concerned that we could be overestimating the damage from protection since local protection comes in many forms, and not all of them involve monetary subsidy. Fortunately, whether local protection involves monetary subsidy is irrelevant for the calculation of consumer surplus. This is because welfare losses only arise when there are choice distortions, and the magnitude solely depends on the gap of the intrinsic utility between a consumer's top choice and the protected product. Monetary subsidies are transfers and don't affect aggregate welfare in the absence of choice distortions.

We use simulations to compare consumer surplus with and without subsidies. For each province, we draw 1000 pseudo consumers using the empirical income distribution and 10,000 random $\varepsilon_{i}$ vectors for each consumer. Then we calculate the monetized difference in the intrinsic utility between a consumer's top choices with and without protection. The intrinsic utility of the top choice without protection is:

$$
\text { Max Utility }=\max _{j=0, \ldots, J}\left\{\tilde{u}_{m t i j}+\varepsilon_{m t i j}\right\}
$$

where $\tilde{u}_{m t i j}$ is the same as that defined in equation (3) but excludes the price discounts for local JVs and SOEs. When we allow for price changes, prices $p_{t j}$ that enter into the calculation of $\tilde{u}_{m t i j}$ are new equilibrium prices in the absence of protection.

The intrinsic utility of the best choice under protection is:

$$
\text { Max Utility } \text { Protection }^{2} \max _{j=0, \ldots, J}\left\{\bar{u}_{m t i j}+\varepsilon_{m t i j}\right\}-\left.\alpha_{m t i} * \rho_{m j t} p_{t k}^{0}\right|_{k=\operatorname{argmax}_{j=0, \ldots, J}\left\{\bar{u}_{i j m}+\varepsilon_{i j m}\right\}}
$$

where $\bar{u}_{i j m}$ is in equation (3), $k$ is the top choice under local protection, and $\rho_{k m t} p_{k t}^{0}$ is the subsidy (price discount) associated with choice $k$. The difference between (11) and (12), averaged across $\varepsilon_{i}$ draws and divided by $\alpha_{m t i}$ (consumer $i$ 's price sensitivity), is the welfare loss associated with choice distortions for consumer $i{ }^{34}$ We average the welfare loss across consumers and multiply it with the market size to obtain the total welfare loss in market $m$ under local protection.

Figure 8 plots total consumer welfare loss between 2009 and 2011 by province for the 15 provinces that have at least one local JV or SOE brands. The other 16 provinces (not shown) are affected by price adjustments only. The blue bars stand for welfare loss directly from choice distortions, and the orange bars add welfare loss from price increases. As expected, welfare loss is higher in larger markets such as Guangdong, and in provinces that are home to more JV and

\footnotetext{
${ }^{33}$ The subsidy is 5,000 yuan in this example, but the consumer welfare loss is equal to 4,000 , which is the difference between the intrinsic utility from his top choice in the absence of protection (10,000 yuan) and his suboptimal choice with protection $(6,000$ yuan).

${ }^{34}$ We have verified that the following approach delivers identical results, where the welfare loss is the difference between total subsidy and changes in consumer surplus from the standard log-sum formula.
} 
especially SOE brands. For example, Anhui only account for $2.9 \%$ of total vehicle sales in China, ranked 13 out of 31 provinces. However, it experiences the fourth highest consumer welfare loss since it is home to two of the largest SOE brands, Chery and JAC.

Figure 8: Consumer welfare loss due to local protection, 2009-2011 (bn. yuan)

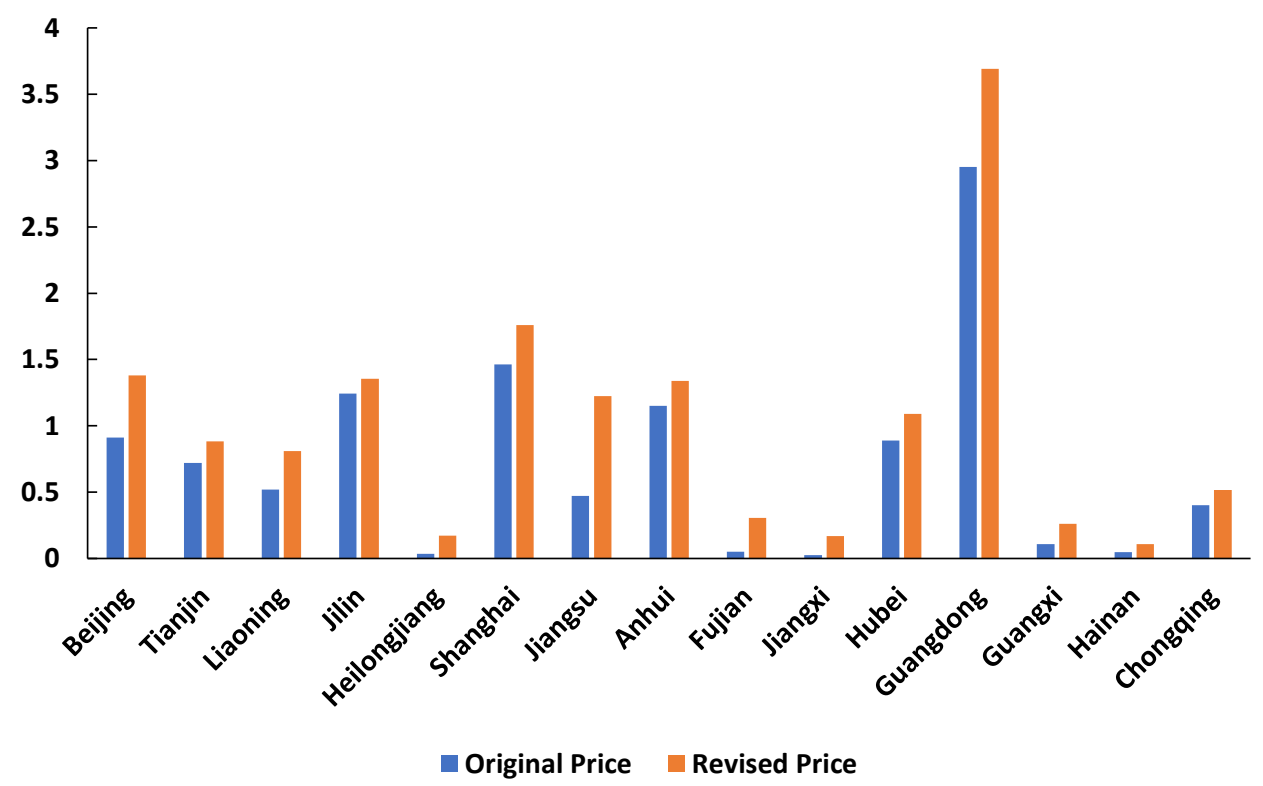

Our simulations suggest that choice distortions directly cost 11.0 billion yuan in consumer welfare between 2009 and 2011. Loss per distorted choice is around 14,000 yuan. After we take into account the impact from price adjustments, total consumer welfare loss is around 18.7 billion yuan, or $\$ 2.8$ billion. To put things into perspective, this is equivalent to $40 \%$ of the total subsidy spent on local production, which is estimated to be 46.3 billion yuan during our sample period.

Subsidies for local products not only create choice distortions, they are also regressive. To demonstrate this, we first simulate households' income tax according to the tax law effective in China between March 2008 and August 2011, and aggregate by income brackets. ${ }^{35}$ Then we simulate the amount of subsidy each income bracket expects to receive.

Table 13 shows how the four income groups are affected by the tax-subsidy scheme. The lowest two income groups account for $90 \%$ of the households, pay $44 \%$ of the taxes, but only receive $29 \%$ of the subsidies. Furthermore, these two bottom income groups account for only $22 \%$ of the direct utility gain (monetized) from the subsidies, which is even smaller than their share of the subsidies. This happens for two reasons. First, poor households have more elastic demand, and often buy cars only with the subsidies. This induces choice distortions and consumer surplus only increases by a fraction of the subsidies. In contrast, rich households can afford to buy cars in the absence of local subsidy. When their optimal choice coincides with or without subsidies, rich households enjoy

\footnotetext{
${ }^{35} \mathrm{We}$ assume one person working in each household.
} 
the full benefits of these subsidies. Second, price increases induced by subsidies offset a larger fraction of welfare gain by the price-sensitive poor households. As a result, the lowest two income brackets shoulder $75 \%$ of the welfare loss, while they account for $42 \%$ of total vehicle sales. The tax-subsidy scheme not only hurts aggregate consumer surplus through choice distortions and price increases, but also creates inequality by hurting the poor households more.

Table 13: Split of tax, subsidy, and welfare loss between income groups

\begin{tabular}{llllll}
\hline \hline Variable & $<48 \mathrm{k}$ & $48 \mathrm{k}-96 \mathrm{k}$ & $96 \mathrm{k}-144 \mathrm{k}$ & $\geq 144 \mathrm{k}$ & Total \\
\hline Number of households & $62 \%$ & $28 \%$ & $6 \%$ & $4 \%$ & $1.3 \mathrm{bn}$. \\
Tax paid & $9 \%$ & $35 \%$ & $22 \%$ & $34 \%$ & $46.3 \mathrm{bn}$. \\
Subsidy received & $7 \%$ & $22 \%$ & $30 \%$ & $41 \%$ & $46.3 \mathrm{bn}$. \\
Utility gain (monetized) from subsidy & $4 \%$ & $18 \%$ & $29 \%$ & $49 \%$ & $27.6 \mathrm{bn}$. \\
Net consumer welfare loss & $16 \%$ & $59 \%$ & $11 \%$ & $14 \%$ & $18.7 \mathrm{bn}$. \\
\hline \hline
\end{tabular}

Turning to auto manufactures, Figure 9 shows the impact of local protection on profits for selected firms of different ownership types (the four colors represent private firms, JVs, SOEs, and foreign firms, respectively). Local protection generally benefits JVs and SOEs at the expense of private automakers and imports, although there is considerable heterogeneity across firms. Among SOEs, Dongfeng and Xiali enjoy a $10 \%$ and $8 \%$ boost in total profits respectively, while Haima experiences a net loss of $1.2 \%$. The fact that some SOEs or JVs are hurt by local protection should not come as a surprise. When home market is small, as is the case of Haima (headquartered in Hainan, a small province that only accounts for $0.5 \%$ of total vehicle sales) and BMW-Brilliance (headquartered in Liaoning, where most households found BMW-Brilliance's luxury products out of reach), losses in non-local markets dominate gains locally.

Since private firms are on average $6 \%$ more cost-efficient than JVs and SOEs, local protection has some long-term repercussions on production efficiency. Table 12 suggests that due to choice distortions, private firms lose to JVs and SOEs around 75,300 units of sales, which translate into a cost increase of around 220 million yuan. While the magnitude of this static impact is small, the long-term consequence could be significant especially if some of the inefficient SOEs cannot survive without local protection. ${ }^{36}$

To quantify the impact of local protection on the aggregate producer surplus, we note that part of the profit increase arises from substitutions from the outside option: some consumers who bought a car because of the subsidies would have chosen the outside option otherwise. When a household does not buy a car, it could be spending money on taxi rides, public transportation, used cars, and other economic activities that generate profits. Such substitutions from the outside option lead to

${ }^{36}$ For example, based on its annual reports, Xiali's net profit from auto production were $2.1 \%, 3.0 \%$, and $1.5 \%$ in 2009 , 2010, and 2011. It would have incurred heavy losses if not for the $8 \%$ boost to profits due to local protection. 
Figure 9: Impact of local protection on firm profits

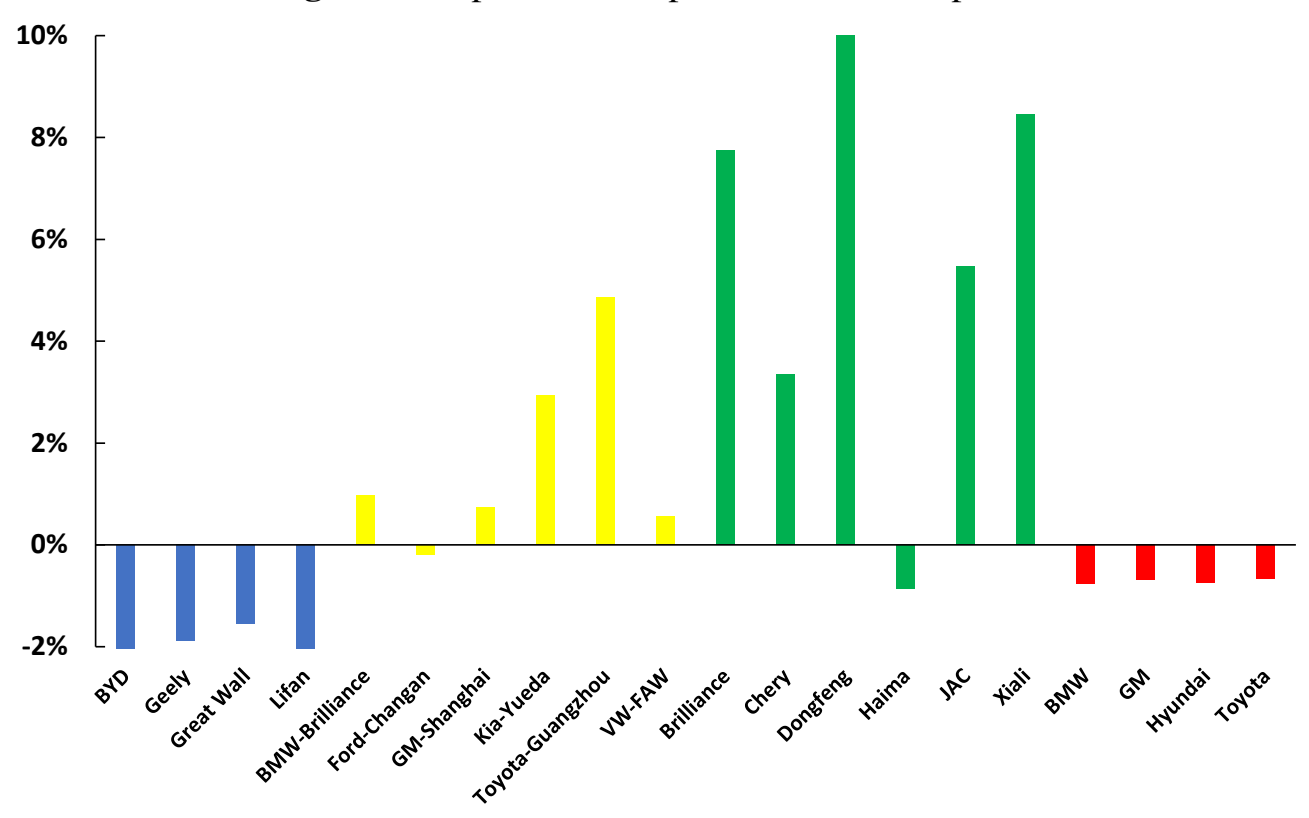

redistribution of producer surplus across industries. A precise statement of the impact of local protection on producer surplus across all industries is beyond the scope of our model. To facilitate comparisons with the consumer surplus, we report separately changes in profit that come from substitution between different vehicles (which only involves the auto industry) and those driven by substitution from the outside option (which also involves redistribution across industries).

Excluding substitutions from the outside option, local protection increases total firm profits by 8.1 billion. Forty-five percent of the increase is due to the modest price hike induced by local protection. The rest is driven by substitutions from private to JVs products, which typically have higher prices and larger profit margins (as well as pay higher taxes). Substitution from the outside option increases auto firms' profit by an additional 2.8 billion yuan.

Local protection raises local governments' tax revenues by 0.6 billion yuan. An additional 3.8 billion yuan of tax revenue accrues to the central government. Putting things together, our analysis suggests that local protection results in a net loss of 6.2-billion yuan in social welfare between 2009 and 2011, which is 18.7 billion yuan reduction in consumer welfare that is partially offset by an increase of 8.1 billion yuan in profit and 4.4 billion yuan in tax revenues.

It is important to note that tax collection is necessary to finance government subsidies and that the marginal excess burden per additional yuan of tax revenue is non-trivial. According to Ballard et al. (1985), the welfare loss from distortionary taxes is in the range of 17 to 56 cents per dollar of extra revenue in the U.S., using elasticity assumptions that appear plausible. The marginal excess burden for tax collection is likely higher in China, since taxed activities tend to be more elastic, market distortions are more severe, and tax evasion is prevalent. The total amount of tax subsidy 
is estimated to be 46.3 billion Yuan during our sample period. If we assume the marginal excess burden is 37 cents per Yuan (the mid point of the range provided by Ballard et al. (1985)), the welfare loss associated with the tax collection to finance these subsidies would amount to 17.1 billion Yuan, nearly three-times the net loss estimated above.

We want to end the discussion here by pointing out that our estimates on the welfare costs of local protection are conservative: they ignore excess burdens of collecting taxes to finance these subsidies, exclude institutional purchases (cars procured by local governments and companies, etc.) that are subjected to even stronger protection, omit subsidies that auto firms receive during the production process, and do not take into consideration long-term consequences of local protection. Aggregate welfare loss could be considerably higher than what we present here.

\subsection{Incentives to protect}

If local protection reduces social welfare and perpetuates production inefficiency, why does it persist? Our simulation demonstrates that without federal oversight, implementing local protection is the dominant strategy for most provincial governments. Regardless of policies implemented in other provinces, protecting local auto firms is the rational decision for all but one province.

For a provincial government, the benefits from implementing local protection have two components. The first is the increase in local profits by firms headquartered in its jurisdiction. This is the only relevant component of total profits because local protection does not affect profits in other markets. ${ }^{37}$ The second component is higher tax revenues. Among the four types of taxes discussed in section 5.2, value-added tax is split $25 \%$ vs. $75 \%$ between local governments and the central government, while the other taxes (sales tax, consumption tax, and import tariff) are collected by the central government. ${ }^{38}$ The cost of local protection is consumer welfare loss due to choice distortions.

Figure 10 compares changes in consumer surplus, producer surplus, and local tax revenue with or without local protection for 10 largest provinces when all other provinces protect local auto firms. Results are nearly identical when we repeat the analysis assuming no other province has local protection (since the price response is minimal). If provincial governments weigh consumer surplus and industry profits equally, implementing local protection is the dominant strategy for all provinces with one exception, the Anhui province. Anhui has two local firms, Chery and JAC. Their products are so inferior relative to vehicles produced elsewhere that consumer losses from choice distortions in Anhui are almost twice as big as gains in profit and local tax revenue. The

\footnotetext{
${ }^{37}$ If a province imposes local protection, it could induce prices changes for all car models, which then affect profits in all markets. However, the price effect is small, as shown in figure 7. In the discussion below, we shut down the price response.

${ }^{38}$ The local government also collects corporate income tax at rate $40 \%$, but most auto firms report minimal income.
} 
fact that the Anhui government subsidizes local brands (see Table 1 and Appendix A) even though this hurts local welfare is consistent with a common perception that government policies in China, most of them being 'top-down', are likely to be influenced by the pursuit of GDP growth and often fail to internalize the impacts on consumer surplus.

Figure 10: Local benefits and costs of local protection

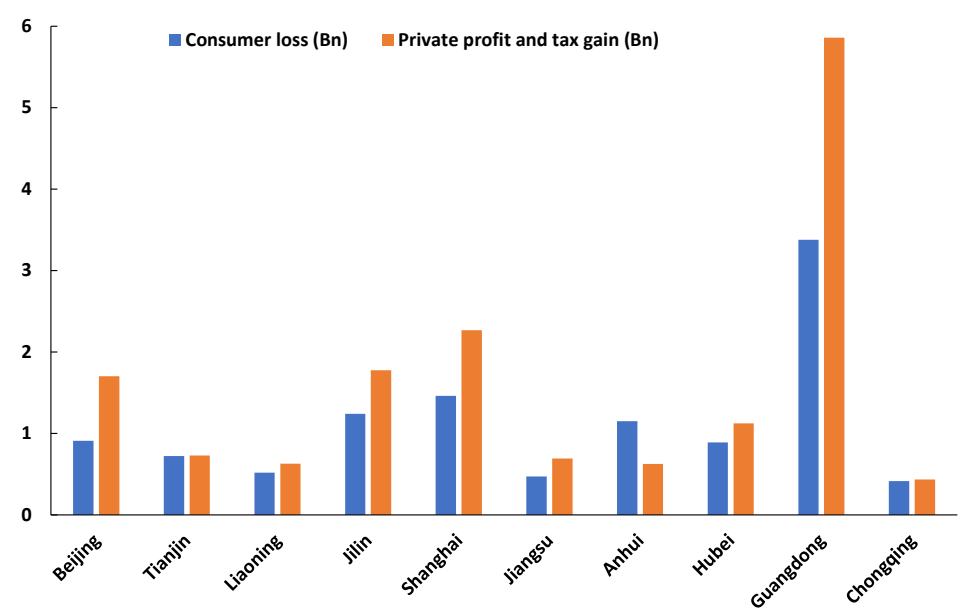

Much of the gain in local profit and tax revenues comes at the expense of non-local firms. For example, although local protection in Shanghai boosts local firms' profits by 2.4 billion yuan, it costs non-local firms 2.1 billion yuan due to business stealing. The aggregate profit and tax gains in Shanghai is a modest 0.3 billion yuan, far below the 1.5 billion yuan of losses suffered by local consumers. Since the provincial governments are likely ignore the negative impacts that local protection imposes on non-local products and profits of non-local firms, our results suggest that they end up in a prisoners' dilemma and local protection persists at the expense of social welfare.

\section{Conclusion}

Based on the census of new passenger vehicle registrations from 2009 to 2011 in China, we provide strong evidence of local protectionism in China's automobile market using a regression discontinuity design, a series of falsification tests, and a number of consumer surveys. Through a structural model of vehicle demand and supply, we then quantify the impacts of local protectionism on market outcomes and show that local protection significantly reduces consumer welfare. In addition, the shift of production from low-cost private firms to high-cost SOEs and JVs would perpetuate production inefficiency and hinder productivity growth. Competition among local governments in protecting their local firms leads to a prisoners' dilemma: while consumers are better off in a world without local protection, local governments have no incentive to abolish local protection unilat- 
erally. Our results indicate that central government policies that could effectively eradicate trade barriers across regions and facilitate market integration within the country would lead to substantial gains in social welfare.

The automobile market in China provides a unique setting to study the formation of brand preferences because most vehicle buyers are still first-time buyers. The literature on the persistence of demand preference suggests that protective policies could have long lasting effects. Even if these policies are eliminated as China embraces more reforms and emulates practices in developed countries, they could still affect future market share dynamics through persistent brand preference. Our welfare estimates could be significantly underestimating the long-term efficiency loss induced by these policies.

While our study is the first to examine the impacts of local protectionism on market outcomes and social welfare focusing on an output market in China, future research could explore its longterm impacts on firm entry and exit, innovation and productivity. This would help us understand the extent to which local protectionism has led to the salient features observed in this industry such as a large number of automakers, production capacity being scattered around the country, and low capacity utilization. Finally, it would be interesting to further explore the incentives of local governments and understand the balances they are trying to strike between consumer welfare, GDP growth, and tax revenue. 


\section{References}

Anderson, James, Catherine Milot, and Yoto Yotov, "How Much Does Geography Deflect Services Trade? Canadian Answers," International Economic Review, 2014, 55, 791-818.

Bai, Chong-En, Yingjuan Du, Zhigang Tao, and Yueting Sarah Tong, "Local Protectionism and Regional Specialization: Evidence from China's Industries," Journal of International Economics, 2004, 63, 397-417.

Ballard, Charles L., John B. Shoven, and John Whalley, "General Equilibrium Computations of the Marginal Welfare Costs of Taxes in the United States," The American Economic Review, 1985,75 .

Berry, Steven, "Estimating Discrete Choice Models of Product Differentiation," RAND Journal of Economics, 1994, 25 (2), 242-262.

_ , James Levinsohn, and Ariel Pakes, “Automobile Prices in Market Equilibrium,” Econometrica, 1995, 63 (4), 841-890.

_, _, and _ , "Voluntary Export Restraints on Automobiles: Evaluating a Trade Policy," American Economic Review, June 1999, 89 (3).

Berry, Steven T. and Philip A. Haile, "Identification in Differentiated Products Markets Using Market Level Data," Econometrica, 2014, 82 (5), 1749-1797.

Brandt, Loren, Trevor Tombe, and Xiaodong Zhu, "Factor market distortions across time, space and sectors in China," Review of Economic Dynamics, 2009, 16, 39-58.

Bronnenberg, Bart J., Jean-Pierre H. Dub, and Matthew Gentzkow, “The Evolution of Brand Preferences: Evidence from Consumer Migration," American Economic Review, 2012, 102, 2472-2508.

Canli, Zeynep Gurhan and Durairaj Maheswaran, "Determinants of Country-of-Origin Evaluations," Journal of Consumer Research, 2000, 27 (1), 96-108.

Cosar, A. Kerem and Pablo D. Fajgelbaum, "Internal Geography, International Trade, and Regional Specialization," American Economic Journal: Microeconomics, 2016, 8, 24-56.

_ , Paul L. Grieco, Shengyu Li, and Felix Tintelnot, "What Drives Home Market Advantage?," 2016. Working Paper.

Dimitropoulos, Alexandros, Jos N. van Ommeren, Paul Koster, and Piet Rietveld, "Welfare Effects of Distortionary Tax Incentives under Preference Heterogeneity: An Application to Employer-provided Electric Cars," 2014. Tinbergen Institute Discussion Paper. 
Donaldson, Dave, "The Gains from Market Integration,” Annual Review of Economics, 2015, 7.

_ , "Railroads of the Raj: Estimating the Impact of Transportation Infrastructure," American Economic Review, 2017.

Dube, Jean-Pierre, Jeremy T. Fox, and Che-Lin Su, "Improving the Numerical Performance of Static and Dynamic Aggregate Discrete Choice Random Coefficients Demand Estimation," Econometrica, 2012, 80 (5).

Faber, Benjamin, "Trade integration, market size, and industrialization: Evidence from china's national trunk highway system," The Review of Economic Studies, 2014, 81:3, 1046-1070.

Fajgelbaum, Pablo D., Eduardo Morales, Juan Carlos Suez Serrato, and Owen Zidar, "State Taxes and Spatial Misallocation,” 2016. Working Paper.

French, Kenneth and James Poterba, "Investor Diversification and International Equity Markets," American Economic Review, 1991, 81.

Gandhi, Amit and Jean-Francois Houde, "Measuring Substitution Patterns in Differentiated Products Industries," 2016. Cornell Working Paper.

Goldberg, Pinelope and Frank Verboven, "Evolution of Price Dispersion in the European Car Market," Review of Economic Studies, 2011, 68, 811-848.

Head, Keith and Thierry Mayer, "Brands in motion: How frictions shape multinational production," 2016. CEPR working paper.

Holmes, Thomas J., Ellen R. McGrattan, and Edward C. Prescott, "Quid Pro Quo: Technology Capital Transfers for Market Access in China*," The Review of Economic Studies, 2015.

Holz, Carsten, "No Razor?s Edge: Reexamining Alwyn Young?s Evidence for In- creasing Interprovincial Trade Barriers in China," Review of Economics and Statistics, 2009, 91, 599-616.

Hsieh, Chang-Tai and Peter J. Klenow, "Misallocation and Manufacturing TFP in China and India," Quarterly Journal of Economics, 2009, 124, 1403-1488.

Jin, Hehui, Yingyi Qian, and Barry R. Weingast, "Regional Decentralization and Fiscal Incentives: Federalism, Chinese Style," Journal of Public Economics, 2005, 89, 1719-1742.

Klein, Jill and Richard Ettensoe, "Consumer Animosity and Consumer Ethnocentrism: An Analysis of Unique Antecedents," Journal of International Consumer Marketing, 1999, 11 (4), 5-24.

Klier, Thomas and Joshua Linn, "Fuel Prices and New Vehicle Fuel Economy - Comparing the United States and Western Europe," Journal of Environmental Economics and Management, 2013, 66, 280-300. 
Knittel, Christopher R. and Konstantinos Metaxoglou, "Estimation of Random-Coefficient Demand Models: Two Empiricists' Perspective," The Review of Economics and Statistics, 2014, 96 (1).

Lei, Yu-Hsiang, "Can Governments Harvest Connections with Firms? Evidence from China," 2017. Working Paper.

Li, Shanjun, Junji Xiao, and Yiming Liu, “The Price Evolution in China's Automobile Market," Journal of Economic Management and Strategy, 2015.

_ , Lang Tong, Jianwei Xing, and Yiyi Zhou, "The Market for Electric Vehicles: Indirect Network Effects and Policy Impacts," Journal of the Association of Environmental and Resource Economists, 2016.

McCallum, John, "National Borders Matter: Canada-U.S. Regional Trade Patterns," American Economic Review, 1995, 85.

Oats, Wallace, Fiscal Federalism, New York: Harcourt Brace Jovanovich, 1972.

Petrin, Amil, "Quantifying the benefit of new products: the case of minivan," Journal of Political Economy, 2002, 110 (4), 705-729.

Shimp, Terence A. and Subhash Sharma, "Consumer Ethnocentrism: Construction and Validation of the CETSCALE," Journal of Marketing Research, 1987, 24.

Young, Alwyn, "The Razor?s Edge: Distortions and Incremental Reform in the People?s Republic of China," Quarterly Journal of Economics, 2000, 115, 1091-1135.

Yu, Rose, Colum Murphy, and Mike Ramsey, "Subsidies Stoke China's Domestic Car Makers," The Wall Street Journal, May 2014. 


\section{Appendices}

\section{A Home bias by firm}

Table A1: Home bias by firm

\begin{tabular}{|c|c|c|c|c|c|}
\hline Firm & $\begin{array}{l}\text { National } \\
\text { Share }\end{array}$ & $\begin{array}{l}\text { Home } \\
\text { Share }\end{array}$ & $\begin{array}{c}\text { Home Bias, } \\
\text { individual }\end{array}$ & $\begin{array}{l}\text { Home Bias, } \\
\text { institutional }\end{array}$ & $\begin{array}{c}\text { Home Bias, } \\
\text { dealers }\end{array}$ \\
\hline \multicolumn{6}{|l|}{ Private Firms } \\
\hline BYD & $4.64 \%$ & $4.83 \%$ & $4 \%$ & $13 \%$ & $19 \%$ \\
\hline Geely & $3.68 \%$ & $2.05 \%$ & $-44 \%$ & $-41 \%$ & $-23 \%$ \\
\hline Great Wall & $2.01 \%$ & $3.28 \%$ & $63 \%$ & $149 \%$ & $3 \%$ \\
\hline Zotye & $0.39 \%$ & $0.28 \%$ & $-28 \%$ & $17 \%$ & $-35 \%$ \\
\hline Lifan & $0.38 \%$ & $0.98 \%$ & $160 \%$ & $128 \%$ & $95 \%$ \\
\hline Hawtai & $0.12 \%$ & $0.10 \%$ & $-20 \%$ & $-100 \%-25 \%$ & \\
\hline \multicolumn{6}{|l|}{ JVs } \\
\hline GM Shanghai & $9.68 \%$ & $17.54 \%$ & $81 \%$ & $117 \%$ & $52 \%$ \\
\hline VW Shanghai & $8.59 \%$ & $24.31 \%$ & $183 \%$ & $71 \%$ & \\
\hline VW FAW & $7.79 \%$ & $21.36 \%$ & $174 \%$ & $177 \%$ & $57 \%$ \\
\hline Hyundai Beijing & $6.46 \%$ & $7.33 \%$ & $13 \%$ & $155 \%$ & $7 \%$ \\
\hline Nissan Dongfeng & $5.61 \%$ & $11.20 \%$ & $100 \%$ & $70 \%$ & $46 \%$ \\
\hline Toyota FAW & $4.88 \%$ & $4.25 \%$ & $-13 \%$ & $142 \%$ & $25 \%$ \\
\hline Ford Changan & $3.91 \%$ & $6.69 \%$ & $71 \%$ & $187 \%$ & $77 \%$ \\
\hline Honda Guangzhou & $3.70 \%$ & $6.97 \%$ & $88 \%$ & $87 \%$ & $86 \%$ \\
\hline PSA Dongfeng & $3.32 \%$ & $11.13 \%$ & $235 \%$ & $689 \%$ & $84 \%$ \\
\hline Kia Yueda & $3.24 \%$ & $3.26 \%$ & $1 \%$ & $39 \%$ & $15 \%$ \\
\hline Honda Dongfeng & $3.70 \%$ & $6.97 \%$ & $93 \%$ & $138 \%$ & $31 \%$ \\
\hline Toyota Guangzhou & $2.44 \%$ & $5.35 \%$ & $119 \%$ & $91 \%$ & $61 \%$ \\
\hline Suzuki Changan & $1.89 \%$ & $2.21 \%$ & $17 \%$ & $742 \%$ & $-1 \%$ \\
\hline Soueast & $0.94 \%$ & $1.38 \%$ & $48 \%$ & $685 \%$ & $37 \%$ \\
\hline GM Shanghai Wuling & $0.82 \%$ & $3.66 \%$ & $345 \%$ & $451 \%$ & $206 \%$ \\
\hline Suzuki Changhe & $0.81 \%$ & $1.35 \%$ & $67 \%$ & $213 \%$ & $150 \%$ \\
\hline BMW Brilliance & $0.63 \%$ & $0.56 \%$ & $-11 \%$ & $4 \%$ & $29 \%$ \\
\hline Daimler beijing & $0.35 \%$ & $0.64 \%$ & $85 \%$ & $148 \%$ & $39 \%$ \\
\hline Zhengzhou Nissan & $0.18 \%$ & $0.50 \%$ & $185 \%$ & $236 \%$ & $49 \%$ \\
\hline Changfeng & $0.03 \%$ & $0.07 \%$ & $133 \%$ & $197 \%$ & $58 \%$ \\
\hline \multicolumn{6}{|l|}{ SOEs } \\
\hline Chery & $4.63 \%$ & $11.63 \%$ & $151 \%$ & $293 \%$ & $67 \%$ \\
\hline FAW & $2.38 \%$ & $7.20 \%$ & $203 \%$ & $379 \%$ & $187 \%$ \\
\hline Xiali & $2.38 \%$ & $16.22 \%$ & $598 \%$ & $475 \%$ & $325 \%$ \\
\hline Chana & $1.50 \%$ & $4.52 \%$ & $201 \%$ & $238 \%$ & $193 \%$ \\
\hline JAC & $1.30 \%$ & $5.43 \%$ & $319 \%$ & $306 \%$ & $132 \%$ \\
\hline SAIG & $1.25 \%$ & $3.04 \%$ & $144 \%$ & $149 \%$ & NA \\
\hline Haima & $1.16 \%$ & $2.63 \%$ & $127 \%$ & $1228 \%$ & $66 \%$ \\
\hline Brilliance & $0.86 \%$ & $3.02 \%$ & $250 \%$ & $482 \%$ & $234 \%$ \\
\hline Dongfeng Liuzhou & $0.41 \%$ & $1.33 \%$ & $222 \%$ & $750 \%$ & $70 \%$ \\
\hline Daihatsu-FAW & $0.31 \%$ & $1.23 \%$ & $303 \%$ & $661 \%$ & $96 \%$ \\
\hline Dongfeng & $0.22 \%$ & $1.82 \%$ & $706 \%$ & $956 \%$ & $321 \%$ \\
\hline Hafei & $0.17 \%$ & $1.16 \%$ & $602 \%$ & $2562 \%$ & NA \\
\hline
\end{tabular}


Table A1 shows the market share in sales by firm at the national level and in the home market where the firm is headquartered. The last column is the percentage difference in the share of dealers at the national level and in the home market, except for SAIG and Hafei for which we do not have data. Most private firms do not fare better in their home markets, every single SOE has stark advantage in its home market, while JVs lie somewhere in-between. The differences in dealer counts are typically below those in sales.

\section{B Regional Variations in Dealer Discounts}

Our analysis is based on MSRPs rather than retail prices since we do not have retail price data for the period studied. Heavy discounts of local products could bias our estimates of home bias. Here we document the promotion patterns based on comprehensive data on dealer promotions in March 2016 from AutoHome.com.cn. Our dataset covers 7,458 trims under 847 vehicle models that are sold in 1,176 counties across all 31 provinces in China. We drop all electric vehicles ${ }^{39}$, which only became available in China in 2014. The total number of observations (trim-store) is 1.5 million. For each trim in each retail store, we calculate its discount rate based on its in-store retail price and MSRP. Table A2 summarizes variations in discount rates across trims and regions.

First, discount rates are typically low, especially for domestic brands. The average discount rate is $5 \%$, and $40 \%$ of trim-by-store observations have no discount. Discount rates are below $10 \%$ for $95 \%$ of trims belonging to domestic brands, while less than $5 \%$ of JV or imported brands have heavy discounts at $20 \%$ or above.

Table A2: Summary Statistics on Discount Rates

\begin{tabular}{lcccccc}
\hline \hline Firm type & No. of trims & \% without discount & Mean & 75th percentile & 95th percentile & Max \\
\hline Private & 147,482 & $51.4 \%$ & $2.4 \%$ & $4.4 \%$ & $9.1 \%$ & $35.1 \%$ \\
JV & 863,488 & $32.7 \%$ & $6.9 \%$ & $11.7 \%$ & $18.8 \%$ & $37.1 \%$ \\
SOE & 246,589 & $49.3 \%$ & $3.3 \%$ & $5.7 \%$ & $12.9 \%$ & $35.1 \%$ \\
Imports & 248,839 & $51.8 \%$ & $4.9 \%$ & $9.4 \%$ & $19.0 \%$ & $35.0 \%$ \\
All & $1,510,846$ & $40.4 \%$ & $5.4 \%$ & $9.9 \%$ & $17.9 \%$ & $63.3 \%$ \\
\hline \hline
\end{tabular}

Second, there are some degree of regional variations in discount rates. Beijing has the highest mean discount rate at $7.6 \%$, while Tibet has the lowest discount at $1.4 \%$. Two thirds of provinces have mean discount rates between $4 \%$ and $6 \%$. Overall, we observe heavier discounts in richer markets such as Beijing, Tianjin, and Shanghai.

\footnotetext{
${ }^{39}$ Some electric vehicles could have heavy discounts up to over $60 \%$ in some counties. These promotions are subsidies from government agencies in an effort to speed up the diffusion of this new technology. Subsidies of similar magnitude for electric vehicles are available in some areas in the U.S. as well (Li et al., 2016).
} 
Finally, we find no evidence that dealer stores give heavier discounts to local product. Table A3 shows results from a trim-level regression of discount rates on home-market dummies. The coefficients are small in magnitude, reflecting the low discount rates on average. After controlling for province and trim fixed effects, the discount rate for private automakers and SOEs are negative, implying that the discounts are actually smaller in the local markets than in other markets. Nevertheless, all three coefficients are small in magnitude (less than 0.5 percentage points) and suggest no economically significant differences in discount rates between the local market and other markets.

Table A3: Regional Variation in Promotions

\begin{tabular}{lllllll}
\hline \hline & \multicolumn{2}{c}{$(1)$} & \multicolumn{2}{c}{$(2)$} & \multicolumn{2}{c}{$(3)$} \\
& Est. & S.E. & Est. & S.E. & Est. & S.E. \\
\hline HQ*Private & $-3.39^{* * *}$ & 0.06 & $-0.18^{* * *}$ & 0.05 & $-0.41^{* * *}$ & 0.05 \\
HQ*SOE & $-2.31^{* * *}$ & 0.05 & 0.04 & 0.04 & $-0.16^{* * *}$ & 0.04 \\
HQ*JV & $1.66^{* * *}$ & 0.03 & $0.37 * * *$ & 0.02 & -0.03 & 0.02 \\
Trim FE & $\mathrm{N}$ & & $\mathrm{Y}$ & & $\mathrm{Y}$ & \\
Province FE & $\mathrm{N}$ & & $\mathrm{N}$ & \multicolumn{2}{c}{$\mathrm{Y}$} & \\
\hline \hline
\end{tabular}

Note: The number of observations is $1,510,846$. The dependent variable is the discount rate (in percentage points). $* \mathrm{p}<0.1, * * \mathrm{p}<0.05, * * * \mathrm{p}<0.01$.

\section{Survey on Dealer Visitors}

This survey is designed to gauge the extent to which consumers are informed about ownership type and location of different automakers as well as the importance of buying local brands in vehicle purchase decisions. The survey instrument is below and are distributed to visitors in four dealership stores in Chongqing in November 2016. Each survey takes about two minutes to fill out and they are collected on site.

We choose to conduct the survey in Chongqing for two reasons. First, it is home to the fourth largest private automaker, LiFan, and the fourth largest SOE, Chana. Second, since Chongqing is much smaller compared to an average province in China in terms of the land area, one would expect its residents to know the local industries better. Therefore, our results should give a conservative estimate of people's lack of knowledge in the local auto industry.

Among 315 surveys deployed, 297 are complete and our analysis is based on these responses. Table A4 presents the summary statistics of the responses by demographic groups. The last row shows the results for the full sample. In column (2), the average score of 2.14 out of 5 on ownership type questions implies that about $40 \%$ of the questions are answered correctly (which is marginally better than a random guess of 33\%). On locations questions, the average score of 3.16 implies that about $60 \%$ of the questions are answered correctly (a random guess would get $50 \%$ right). Out of all respondents, only one correctly answered all 10 questions. About $43 \%$ of respondents consider 


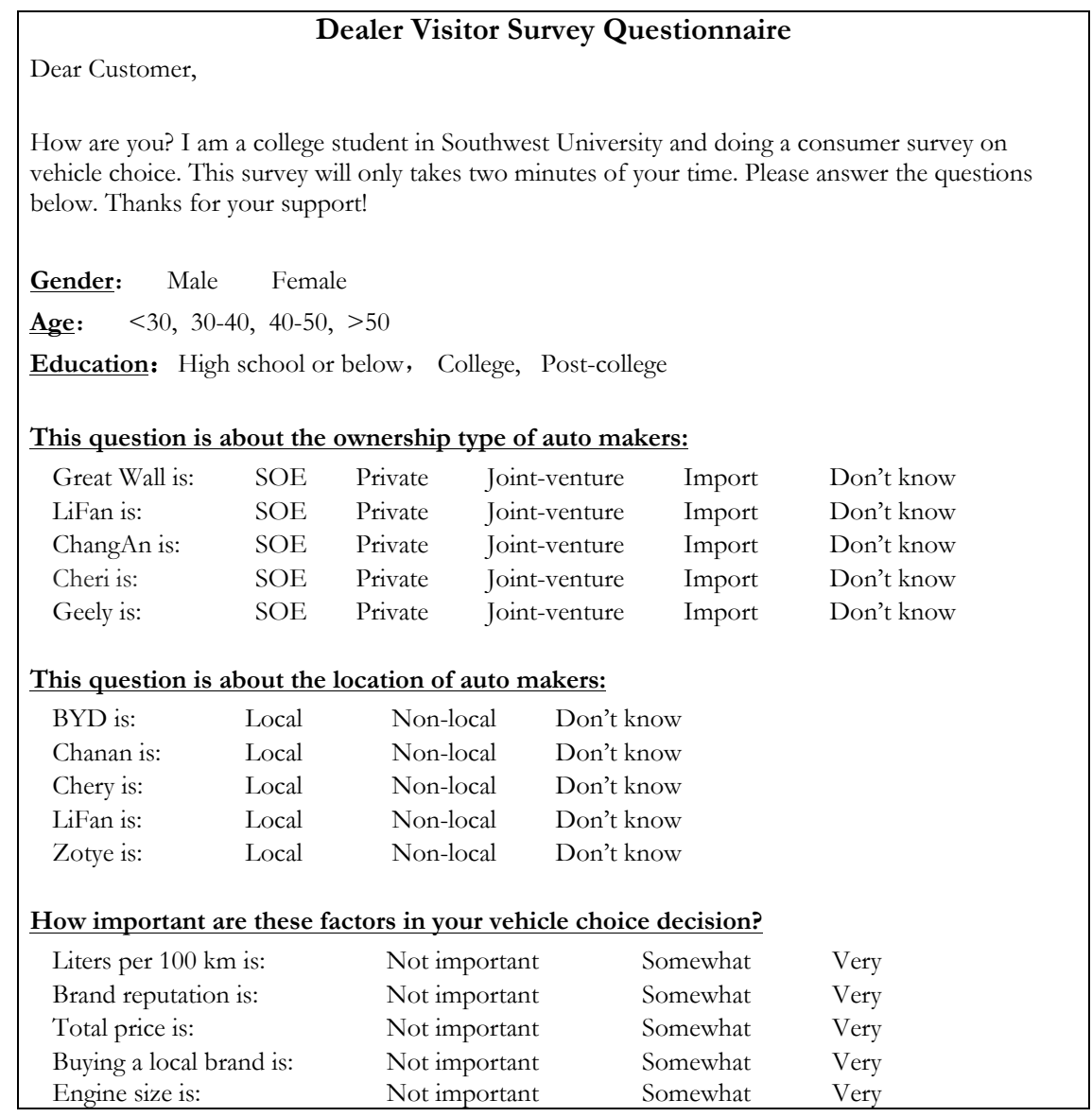

buying local brands as being not important at all in their purchase decisions while only $14 \%$ and $28 \%$ of them consider price and brand reputation as being not important, respectively.

Male respondents on average are slightly more informed than their female counterparts. They are also less concerned about local brands and vehicle prices in their purchase decisions relative to female respondents although the differences are small. Age but not education seems to help with knowledge on ownership type and location of automakers. Younger buyers tends to care less about local brands but more about price and reputation. 
Table A4: Summary Statistics by Demographics

\begin{tabular}{|c|c|c|c|c|c|c|}
\hline \multirow[b]{2}{*}{ Demographics } & \multirow[b]{2}{*}{$\begin{array}{c}\text { Percent } \\
\text { (1) }\end{array}$} & \multicolumn{2}{|c|}{ Mean score (out of 5) } & \multicolumn{3}{|c|}{ Factors not important } \\
\hline & & $\begin{array}{c}\text { Ownership type } \\
\text { (2) }\end{array}$ & $\begin{array}{c}\text { Local or not } \\
\text { (3) }\end{array}$ & $\begin{array}{c}\text { Local or not } \\
(4)\end{array}$ & $\begin{array}{c}\text { Price } \\
(5)\end{array}$ & $\begin{array}{c}\text { Reputation } \\
(6)\end{array}$ \\
\hline \multicolumn{7}{|l|}{ Gender } \\
\hline Female & 46.5 & 2.11 & 3.07 & 42.0 & 12.3 & 28.3 \\
\hline Male & 53.5 & 2.17 & 3.25 & 43.4 & 15.1 & 28.3 \\
\hline \multicolumn{7}{|l|}{ Age } \\
\hline$<30$ & 32.3 & 2.01 & 2.91 & 51.0 & 14.6 & 26.0 \\
\hline $30-40$ & 34.7 & 2.02 & 3.10 & 35.0 & 15.5 & 28.2 \\
\hline $40-50$ & 24.6 & 2.47 & 3.42 & 42.5 & 9.6 & 27.4 \\
\hline$>50$ & 8.4 & 2.20 & 3.64 & 44.0 & 16.0 & 40.0 \\
\hline \multicolumn{7}{|l|}{ Education } \\
\hline$\leq$ High school & 40.7 & 2.32 & 3.43 & 43.0 & 11.6 & 32.2 \\
\hline College & 39.7 & 2.02 & 3.03 & 40.7 & 16.9 & 22.0 \\
\hline Post-college & 19.5 & 2.02 & 2.88 & 46.6 & 12.1 & 32.8 \\
\hline All & 100.0 & 2.14 & 3.16 & 42.8 & 13.8 & 28.3 \\
\hline
\end{tabular}

Notes: There are five questions on the ownership type of automakers and five questions on whether an automaker is local or not. Column(1) shows the percentage of respondents by demographic groups. Columns (2) and (3) present the average scores on the two sets of questions. Columns (4) to (6) show the percentage of respondents who consider each factor being not important in their vehicle purchase decisions. The other two factors that are not shown in the table are fuel economy and engine size. In terms of the percentage of respondents who consider them being not important, they are in between brand reputation and price. 